\title{
Environmental Inequality and Economic Valuation
}

\author{
Jasper N. Meya ${ }^{1,2}$
}

Accepted: 15 April 2020 / Published online: 15 May 2020

(c) The Author(s) 2020

\begin{abstract}
I study how the economic value of a heterogeneously distributed environmental public good depends on how the endowment with this good and income are distributed. I find that the effect of environmental inequality on the societal willingness to pay (WTP) for the environmental good is determined both by its substitutability and by the correlation of its provision with income. Specifically, environmental inequality decreases societal WTP for substitutes, but this effect is reversed if the environmental good is a complement or distributed strongly in favour of richer households. Moreover, I show that richer households living in places where environmental good endowment is high increases (decreases) societal WTP if and only if the environmental good is a substitute for (complement to) consumption goods. I propose novel adjustment factors for structural benefit transfer to control for differences in the spatial distribution of environmental goods. Using forest preservation in Poland as an empirical example, I find that societal WTP is up to $4 \%$ higher for equal access to forests and up to $8 \%$ higher for an equal distribution of both income and access to forests.
\end{abstract}

Keywords Inequality $\cdot$ WTP $\cdot$ Heterogeneously distributed public good $\cdot$ Spatial distribution $\cdot$ Benefit transfer $\cdot$ Forest ecosystem services

JEL Classification D63 - Q51

\section{Introduction}

Environmental policy making is increasingly informed by economic values assigned to non-market environmental goods (e.g. OECD 2018), which are often distributed highly unequal among households. For instance, Boyce et al. (2016) recently found that exposure to industrial air pollution in the United States is even more unequally distributed than income. In many cases such environmental inequalities reinforce prevailing economic inequalities: For centuries, wealthy citizens have tended to live in areas where environmental

Jasper N. Meya

jasper.meya@idiv.de

1 Department of Economics, Leipzig University, Leipzig, Germany

2 Biodiversity Economics Group, German Centre for Integrative Biodiversity Research (iDiv) HalleJena-Leipzig, Deutscher Platz 5e, 04103 Leipzig, Germany 
quality is high, while pollution has been burdened disproportionately on poor citizens. ${ }^{1}$ As biodiversity change and the loss of many environmental goods is accelerating (IPBES 2019; Baumgärtner et al. 2015; Butchart et al. 2010; MEA 2005) and income is distributed increasingly unequal in most parts of the world (Alvaredo et al. 2017), it is timely to study the interplay of environmental and income inequalities.

The monetary valuation of non-market goods has become a central challenge for environmental economics. So far, however, valuation studies have paid little attention to the implications of environmental inequalities and their (spatial) coupling with income inequalities (Drupp et al. 2018). Recently, Baumgärtner et al. (2017a) presented a model of how the distribution of income affects the societal value of a homogeneously distributed public good at the stage of aggregating individual values. For an equal preference model set-up in which all households are endowed with the same level of an environmental good but differ in exogenously given income, they find that societal willingness to pay (WTP) decreases (increases) with income inequality if and only if the environmental good is a substitute for (complement to) manufactured consumption goods. As the majority of environmental goods considered in non-market valuation are unevenly distributed across households, it is crucial to extend this model framework to heterogeneously distributed public goods and to analyze how environmental inequalities affect societal WTP.

In this paper, I study how the joint distribution of exposure and income-and in particular, environmental and income inequality - affect the value of a public good. I present a model of societal WTP for an environmental public good where households differ in both environmental good endowment and income. ${ }^{2}$ Taking the homogenous public good model of Baumgärtner et al. (2017a) as point of departure, I assume (a) households to have identical preferences regarding a manufactured private consumption good and an exogenously given environmental good represented by a constant elasticity of substitution (CES) utility function, and (b) differ in log-normally distributed household income. I extend their model to the case of heterogeneously distributed public goods by assuming (c) that households are heterogeneous in their endowment with a rationed environmental good, represented by a log-normal distribution. While the later is certainly an approximation, the assumption of log-normality reflects that the access or exposure to environmental goods across households is in many cases strongly right-skewed and positive. This model setting allows to study the novel aspects of environmental inequality and the correlation of environmental good endowment with income as determinants of societal WTP.

I find that the distribution of the environmental good-and how this is correlated with income-affects societal WTP. In particular, I show that (1) the effect of environmental and income inequality on societal WTP is determined by whether the environmental good is a substitute for or a complement to manufactured consumption goods and by how environmental good endowment is correlated with income; (2) a higher correlation between income and environmental good endowment, i.e. richer households enjoying more of the environmental good, increases (decreases) societal WTP if and only if the environmental good is a substitute for (complement to) manufactured consumption goods. Based on these

\footnotetext{
1 For instance, Lee and Lin (2018) show that in the period from 1880 to 2010, U.S. metropolitan neighborhoods close to environmental amenities increase in income over time, and that cities with a pronounced heterogeneous distribution of natural amenities are also characterized by a persistent heterogeneous spatial distribution of income. Heblich et al. (2018) show that in 90 English cities, air pollution around 1880 explains a large share of both the historical and current spatial income distribution.

2 Societal WTP in this paper is measured as the sum, or equivalently the mean, of individual WTPs.
} 
theoretical insights, I derive theory-based adjustment factors for benefit transfer to account for differences in the distribution of environmental goods and income. Finally, an application to forest preservation in Poland illustrates economic effect sizes of the proposed adjustments in the range of several percentage points.

My research adds in particular to two strands of literature: First, I contribute to the development of theory-based ('structural') methods for spatial benefit transfer. Practical policy analysis usually draws on monetary values from past studies to inform policy making in a different context (OECD 2018), which is commonly referred to as 'benefit transfer' or 'value transfer'. As the associated errors are often large, several scholars have argued that benefit transfers should be based more firmly in micro-economic theory (Bateman et al. 2011; Smith et al. 2002). Indeed, benefit transfer functions specified purely based on statistical fit, might be theoretically inconsistent (Moeltner 2019; Newbold et al. 2018). Recently, there has been a growing interest in spatially explicit approaches to benefit transfer (e.g. Kuminoff 2018; Turner 2017; Perino et al. 2014; Brander et al. 2012). In the present paper, I add to this literature by developing a structural benefit transfer approach for the valuation of spatially distributed environmental public goods.

Second, I contribute to the literature on spatial inequality and neighborhood sorting. My analysis is thus related to Brueckner et al. (1999), Lee and Lin (2018), Heblich et al. (2018), who show that environmental amenities induce neighborhood sorting, with higherincome households sorting into neighborhoods where environmental quality is high. In a seminal paper Epple and Platt (1998) firstly developed a more general neighborhood sorting model where households differ in both income and preferences, ${ }^{3}$, resulting in twodimensional household stratification. In this class of models, conditional on preferences, richer households sort into places with higher environmental good endowment. The correlation between environmental quality and socio-demographic variables such as income has been scrutinized under the headline of 'environmental justice' for decades (e.g. Ash and Fetter 2004; Banzhaf et al. 2019). Here, I link the societal valuation of environmental amenities to sorting by analyzing differences in the correlation between environmental goods and income.

The remainder is structured as follows. I present the model in Sect. 2, and the results from the model analysis in Sect. 3. An empirical application for a forest protection policy in Poland is presented in Sect. 4. I discuss limitations of my analysis in Sect. 5 and conclude in Sect. 6. The appendix contains all formal proofs.

\section{Model}

I extend the homogenous public good model developed in Baumgärtner et al. (2017a) to make it applicable to spatially heterogeneously distributed public goods. Consider a society that consists of a continuum of households. This might be a city, region, or country. There is a single environmental amenity providing an environmental good that households enjoy at different levels. Several households might be endowed with the same level of the environmental good. ${ }^{4}$ A household $i$ derives utility by consuming two goods: a private, manufactured consumption good, $X_{i}>0$, traded on a market at price $P>0$, and the

\footnotetext{
3 Epple and Sieg (1999) provide a first empirical estimation of this model. For an application to ozone concentrations see Smith et al. (2004). Kuminoff et al. (2013) give an overview on this literature.

4 By 'environmental good' I refer to all types of goods and services people receive from nature. In the following, I study an environmental good that is public, i.e. non-excludable and non-rival, and heterogeneously distributed over space so that exposure or access varies across households within a society. My analy-
} 
non-market-traded, public environmental good, $E_{i}>0$. The household cannot choose the level of the environmental good, which is exogenously fixed at quantity $E_{i}$. Household $i$ 's endowment with the environmental good, $E_{i}$, might be measured in physical units, for example 'parts per million', 'park area density' or 'distance to the nearest environmental amenity' such as an urban park or forest.

Households have equal preferences regarding these two goods, represented by a constant elasticity of substitution (CES) utility function

$$
U\left(X_{i}, E_{i}\right)=\left(\alpha X_{i}^{\frac{\theta-1}{\theta}}+(1-\alpha) E_{i}^{\frac{\theta-1}{\theta}}\right)^{\frac{\theta}{\theta-1}},
$$

where $\theta \in(0,+\infty)$ is the constant elasticity of substitution between the market-traded consumption good and the non-market-traded environmental good. The other preference parameter $\alpha \in(0,1)$ measures the weight of the consumption good relative to the environmental good in the household's overall utility. The CES utility function is the simplest preference representation that is still rich enough to study different degrees of substitutability in the consumption of the environmental good and manufactured goods. It contains the cases where both are substitutes $(\theta>1)$, Cobb-Douglas $(\theta=1)$ and complements $(\theta<1)$.

To obtain the virtual price or marginal WTP, $\omega$, for the environmental good, I draw on the "standard [...] rationed model of consumption" (Flores and Carson 1997, p. 288), where a public good is consumed in fixed quantity. One may consider the hypothetical decision problem, where Household $i$ 's maximizes utility from a freely-chosen aggregated consumption good, $X_{i}$, subject to a budget constraint given by their income, $Y_{i}>0$, and to the exogenously fixed level $E_{i}$ (cf. Flores and Carson 1997, p. 288; Ebert 2003, p. 439; Baumgärtner et al. 2017a, Eq. 2): ${ }^{5}$

$$
\max _{X_{i}} U\left(X_{i}\right) \quad \text { s.t. } \quad P X_{i}=Y_{i}, \quad E_{i} \text { fixed. }
$$

Marginal WTP can then be derived from household $i$ 's indirect utility function at the currently enjoyed level of the environmental good, $E_{i}$, the market prices of consumption goods, $P$, and income, $Y_{i}$ (see Appendix 1.1). As only a single, aggregated consumption good $X_{i}$ is considered here, Eq. (2) implies that the household spends all income on $X_{i}$.

Equivalently, this marginal WTP can be obtained by considering the hypothetical choice problem, where household $i$ chooses both $X_{i}$ and $E_{i}$ to maximize utility subject to a hypothetical (or virtual) budget constraint and constant income (Flores and Carson 1997, p. 289; Ebert 2003, Eq. 1):

\footnotetext{
Footnote 4 (continued)

sis therefore applies mainly to use values as opposed to non-use values, which generally do not depend on exposure or access. For example, one may think of regulatory ecosystem services such as clean air and cultural ecosystem services such as recreation opportunities provided by urban green spaces or forests. For the sake of brevity, I only refer to $E$ as environmental good in the following. Nevertheless, the analysis equally holds for a reduction in environmental bads, such as local air pollution or environmental disamenities such as hazardous waste sites or highways.

5 To save on notation, I use $E_{i}$ to denote both the variable 'household $i$ 's endowment with the environmental good' and the actual consumed quantity, as the consumed quantity $E_{i}$ is fixed throughout the main analysis (see "Appendix 1.7” for how this assumption might be relaxed).
} 


$$
\max _{X_{i}, E_{i}} U\left(X_{i}, E_{i}\right) \quad \text { s.t. } \quad P X_{i}+\omega E_{i}=\hat{Y}_{i},
$$

where $\hat{Y}_{i}=Y_{i}+\omega E_{i}$ as the household does not actually pay for $E_{i}$ in this hypothetical decision. The marginal WTP (so called 'Lindahl price'), $\omega$, is the price the household would have been willing to pay if the level of the environmental good that the household enjoys, $E_{i}$, had been freely chosen on a hypothetical market.

Following Aaron and McGuire (1970), Ebert (2003) and Baumgärtner et al. (2017a) I define household $i$ 's total WTP for the environmental good at level $E_{i}$ as the marginal WTP, $\omega$, per unit of the environmental good at level $E_{i}$ times the enjoyed quantity of $E_{i}$ : $\mathrm{WTP}\left(Y_{i}, E_{i}\right):=\omega\left(Y_{i}, E_{i}\right) E_{i}$. This benefit or value concept is suitable for applications, where the whole environmental good is valued with a single price, as common in natural capital accounting (e.g. United Nations et al. 2014) or applied benefit transfer (e.g. European Commission 2013). Defined this way, total WTP provides an income-equivalent measure (cf. Aaron and McGuire 1970), that does not include consumer surplus and allows direct comparison of the distribution of environmental benefits and income (Ebert 2003). Since income equals the price times the quantity of the private goods consumed, $Y_{i}=P X_{i}$, total WTP, defined also as (Lindahl) price times (environmental good) quantity, follows the same logic as the evaluation of private goods and gives a measure in income (Ebert 2003). ${ }^{6}$

For the CES utility function, household $i$ 's total WTP for the environmental good at level $E_{i}$ can be expressed as a function of income, $Y_{i}$, price level, $P$, and preference parameters, $\alpha$ and $\theta$, as follows ("Appendix 1.1"):

$$
\operatorname{WTP}\left(Y_{i}, E_{i}\right)=w\left(Y_{i}, E_{i}\right) E_{i}, \quad \text { where } \quad w\left(Y_{i}, E_{i}\right)=\frac{1-\alpha}{\alpha} P^{\frac{\theta-1}{\theta}} E_{i}^{-1 / \theta} Y_{i}^{1 / \theta}
$$

is the marginal WTP for the environmental good. Equation (4) implies that the elasticity of substitution, $\theta$, between the manufactured consumption good, $X_{i}$, and the environmental good, $E_{i}$, is the inverse of the income elasticity of WTP, $\eta$, which consequently is also constant. ${ }^{7}$ As most approaches to benefit transfer are based on a constant income elasticity of WTP, this property makes the CES utility framework the preferred functional form to deduct benefit transfer factors in the following. While the inverse relationship, $\eta=1 / \theta$, plays no role for the remainder theoretical analysis, it eases interpretations and is handy for empirical applications (see Sect. 4) as $\theta$ is not directly observable. ${ }^{8}$

Recall that households have heterogeneous exposure to the environmental good, which they enjoy at different exogenously fixed levels $E_{i}$. In order to model this heterogeneous distribution, I assume that the environmental good is unevenly and continuously distributed over households, represented by a log-normal distribution,

\footnotetext{
6 The appropriate value or benefit measure depends on the purpose of valuation. Alternatively, total benefits from consuming $E_{i}$ could be measured by a Hicksian welfare measure like compensating or equivalent variation. These would be suitable for applications, where, among others, consumer surplus is of interest. I show in "Appendix 1.10", that total WTP defined as compensating surplus is given as $\operatorname{WTP}\left(Y_{i}, E_{i}\right)=\frac{\omega\left(Y_{i}, E_{i}\right)}{P} d E_{i}$, where $d E_{i}$ is the marginal change in $E_{i}$.

7 The relationship $\eta=1 / \theta$ for CES preferences is already well established (Baumgärtner et al. 2017a; Ebert 2003; Kovenock and Sadka 1981). Ebert (2003) has shown that for a general ordinal utility function $U\left(X_{i}, E_{i}\right)$, the income elasticity of WTP, $\eta$, depends inversely of the elasticity of substitution, $\theta$, between $X_{i}$ and $E_{i}$ and is proportional to the income elasticity of demand, $\xi$, for $E_{i}$, i.e. $\eta=\xi / \theta$ (see Ebert 2003, Result 9, p. 451). For CES preferences the income elasticity of demand equals one, $\xi=1$.

${ }^{8}$ In contrast to $\theta$, the income elasticity of WTP, $\eta$, has been elicited in a number of stated preference studies and mostly found to be below unity (Drupp 2018; Kriström and Riera 1996).
} 


$$
E_{i} \propto \ln \left(\mu_{E} ; \sigma_{E}^{2}\right)
$$

where $\mu_{E}>0$ is the mean level of the environmental good and $\sigma_{E}$ is the spread of environmental good endowment across households. The frequency of households having access or exposure to a certain level of the environmental good is given by the corresponding density function. Assuming a log-normal distribution reflects that the endowment with environmental goods is positive and that some households in society enjoy a higher level of the environmental good than the majority of households - for instance, households living very close to environmental amenities. The assumption of log-normality is in line with empirical evidence that in many cases environmental good endowment is strongly right-skewed (see Sect. 5).

Households are also heterogeneous in income, represented by a log-normal distribution

$$
Y_{i} \propto \ln \left(\mu_{Y} ; \sigma_{Y}^{2}\right)
$$

where $\mu_{Y}>0$ is the level of mean income and $\sigma_{Y}$ is the spread of the income distribution in the society. Empirical evidence supports this assumption of log-normality as a fairly good approximation for many national income distributions as well as the global distribution of income (Pinkovskiy and Sala-i-Martin 2009).

In this setting, society's mean WTP (or 'sociatel WTP'), $\mu_{\mathrm{WTP}}$, for the environmental good can be formulated as expected value

$$
\mu_{\mathrm{WTP}}\left(\mu_{Y}, \sigma_{Y}, \mu_{E}, \sigma_{E}, \rho\right)=\int_{0}^{\infty} \int_{0}^{\infty} f_{\ln }\left(Y, E ; \mu_{Y}, \sigma_{Y}, \mu_{E}, \sigma_{E}, \rho\right) \operatorname{WTP}(Y, E) d Y d E,
$$

where $f_{\ln }\left(Y, E ; \mu_{Y}, \sigma_{Y}, \mu_{E}, \sigma_{E}, \rho\right)$ is the continuous density function of the bivariate log-normal distribution for income, $Y$ - with mean $\mu_{Y}$ and standard deviation $\sigma_{Y}$-and the environmental good, $E$ - with mean $\mu_{E}$ and standard deviation $\sigma_{E}$-and their correlation, $\rho$.

The density function of the bivariate log-normal distribution is (e.g. Yue 2000)

$$
\begin{aligned}
& f_{\ln }\left(Y, E ; \mu_{Y}, \sigma_{Y}, \mu_{E}, \sigma_{E}, \rho\right) \\
& =\frac{\exp \left[-\frac{1}{2\left(1-\rho^{2}\right)}\left(\frac{\left(\ln (Y)-m_{Y}\right)^{2}}{s_{Y}^{2}}-2 \rho \frac{\ln (Y)-m_{Y}}{s_{Y}} \frac{\ln (E)-m_{E}}{s_{E}}+\frac{\left(\ln (E)-m_{E}\right)^{2}}{s_{E}^{2}}\right)\right]}{2 \pi Y E \sqrt{s_{Y}^{2} s_{E}^{2}\left(1-\rho^{2}\right)}}, \\
& \text { with } \quad m_{j}=\ln \left(\mu_{j}\right)-\frac{1}{2} \ln \left(1+\frac{\sigma_{j}^{2}}{\mu_{j}^{2}}\right), \quad s_{j}^{2}=\ln \left(1+\frac{\sigma_{j}^{2}}{\mu_{j}^{2}}\right), \quad j \in\{Y, E\},
\end{aligned}
$$

where $\rho \in(-1,1)$ is the product-moment correlation coefficient of $Y$ and $E .^{9}$ The bivariate log-normal distribution contains the cases where income and endowment with the environmental good are positively correlated $(\rho>0)$, negatively correlated $(\rho<0)$, or distributed independently $(\rho=0)$. While all three cases seem plausible, several empirical studies report a positive correlation between income and the endowment with environmental

\footnotetext{
9 The product-moment correlation coefficient (often also referred to as Pearson correlation coefficient), $\rho$, is defined as $\rho(Y, E)=\frac{\mathbf{E}\left[\left(Y-\mu_{Y}\right)\left(E-\mu_{E}\right)\right]}{\sigma_{Y} \sigma_{E}}$, where $\mathbf{E}[\cdot]$ is the expected value. Applied to a sample with $\left\{Y_{1}, \ldots, Y_{N}\right\}$ and $\left\{E_{1}, \ldots, E_{N}\right\}$, the sample Pearson correlation coefficient, $r$, is $r=\frac{\sum_{1}^{N}\left(Y_{i}-\mu_{Y}\right)\left(E_{i}-\mu_{E}\right)}{\sqrt{\sum_{1}^{N}\left(Y_{i}-\mu_{Y}\right)^{2}} \sqrt{\sum_{1}^{N}\left(E_{i}-\mu_{E}\right)^{2}}}$, where $\mu_{Y}$ and $\mu_{E}$ are the sample means.
} 
goods such as urban green spaces (Jensen et al. 2016; Tan and Samsudin 2017) or air quality (Ash and Fetter 2004; Hsiang et al. 2019).

Mean WTP can then be expressed as a function of the moments- $\mu_{Y}, \sigma_{Y}, \mu_{E}, \sigma_{E}, \rho-$ of the distribution of income and environmental good endowment (see Appendix 1.2):

$$
\begin{gathered}
\mu_{\mathrm{WTP}}\left(\mu_{Y}, \mathrm{CV}_{Y}, \mu_{E}, \mathrm{CV}_{E}, \rho\right)=\frac{1-\alpha}{\alpha} P^{\frac{\theta-1}{\theta}} \mu_{Y}^{\frac{1}{\theta}}\left(1+\mathrm{CV}_{Y}^{2}\right)^{\frac{1-\theta}{2 \theta^{2}}} \mu_{E}^{\frac{\theta-1}{\theta}}\left(1+\mathrm{CV}_{E}^{2}\right)^{\frac{1-\theta}{2 \theta^{2}}} \Psi \\
\text { with } \quad \Psi\left(\mathrm{CV}_{Y}, \mathrm{CV}_{E}, \rho\right):=\exp \left[\rho \frac{\theta-1}{\theta^{2}} \sqrt{\ln \left(1+\mathrm{CV}_{E}^{2}\right) \ln \left(1+\mathrm{CV}_{Y}^{2}\right)}\right],
\end{gathered}
$$

where the coefficients of variation $\mathrm{CV}_{Y}:=\frac{\sigma_{Y}}{\mu_{Y}}$ and $\mathrm{CV}_{E}:=\frac{\sigma_{E}}{\mu_{E}}$ describe the spread of the distribution of income and the environmental good relative to their mean level. In the following I employ $\mathrm{CV}_{Y}$ and $\mathrm{CV}_{E}$ as measures for relative income inequality and relative environmental inequality, respectively. ${ }^{10}$ When all households are exposed to the same amount of the environmental good, i.e. $\sigma_{E}=0$ or equivalently $\mathrm{CV}_{E}=0$, mean WTP for the environmental good in Eq. (10), reduces to the case of a homogeneously distributed public good, $\forall i: E_{i}=E$, studied by Baumgärtner et al. (2017a).

When income and environmental good endowment are distributed independently, $\rho=0$, then the last term in Eq. (10) becomes one, $\Psi\left(\mathrm{CV}_{Y}, \mathrm{CV}_{E}, \rho\right)=1$, and the expression for mean WTP reduces to

$$
\mu_{\mathrm{WTP}}^{\mathrm{ind}}\left(\mu_{Y}, \mathrm{CV}_{Y}, \mu_{E}, \mathrm{CV}_{E}\right)=\frac{1-\alpha}{\alpha} P^{\frac{\theta-1}{\theta}} \mu_{Y}^{\frac{1}{\theta}}\left(1+\mathrm{CV}_{Y}^{2}\right)^{\frac{1-\theta}{2 \theta^{2}}} \mu_{E}^{\frac{\theta-1}{\theta}}\left(1+\mathrm{CV}_{E}^{2}\right)^{\frac{1-\theta}{2 \theta^{2}}},
$$

which is an import special case as the terms for income inequality and environmental inequality factorize. It follows directly that the key result of Baumgärtner et al. (2017a) on how income inequality affects mean WTP for homogeneously distributed public goods can be generalized to heterogeneously distributed public goods that are distributed independently of income.

In the following, I conduct comparative statics with respect to marginal changes in income inequality, $\mathrm{CV}_{Y}$, and in the distribution of the environmental good $\left(\mathrm{CV}_{E}, \rho\right)$. Marginal changes in the distribution of the environmental good can be understood as various stylized, not explicitly modelled environmental policies: Increases (decreases) in $\mathrm{CV}_{E}$ can be interpreted as environmental policies that decrease (increase) equity in the endowment with environmental goods. Increases (decreases) in $\rho$ can be interpreted as environmental policies that increase (decrease) the endowment of richer households with environmental goods relative to poorer households or as the effect of some exogenous, not-modelled neighborhood sorting.

\footnotetext{
${ }^{10}$ In the remainder I focus on the coefficient of variation as measure of spread to facilitate comparisons between environmental and income inequality. Thus, I conduct a variable transformation where $\sigma_{j}$ is replaced by a function $\mathrm{CV}_{j}\left(\sigma_{j}\right)$ which scales $\sigma_{j}$ by $\mu_{j}$ with $j \in Y, E$.
} 


\section{Results of Model Analysis}

\subsection{Societal WTP for the Heterogeneously Distributed Environmental Good}

I am now prepared to study how mean WTP for the environmental good, $\mu_{\mathrm{WTP}}$ [Eq. (10)], changes with a marginal change in (1) income inequality, $\mathrm{CV}_{Y},(2)$ environmental inequality, $\mathrm{CV}_{E}$, or (3) the correlation between income and environmental good endowment, $\rho$. While I report all results for the elasticity of substitution, these could also be interpreted for the income elasticity of WTP by simply substituting $\theta=1 / \eta$.

Question 1 How does income inequality affect society's mean WTP for the environmental good?

First, I am interested in how the mean WTP for the environmental good changes with a marginal change in income inequality or environmental inequality. I assume that there is some inequality in income and the some heterogeneity in environmental good endowment, $\mathrm{CV}_{Y}, \mathrm{CV}_{E}>0$. These assumptions are necessary to differentiate mean WTP given in Eq. (10) with respect to income inequality, $\mathrm{CV}_{Y}$, and environmental inequality, $\mathrm{CV}_{E}$. Note that I assume the correlation between income and the exposure to the environmental good to remain unchanged, while evaluating the sign of the mean WTP function for a marginal change in income inequality or environmental inequality. I conduct this stepwise for the case that the distribution of the environmental good is correlated with income $(\rho \neq 0)$ and for the important special case that the environmental good and income are distributed independently $(\rho=0)$, which generates simpler results.

Proposition 1 Mean WTP for the environmental good, $\mu_{\mathrm{WTP}}$, decreases (increases) with relative income inequality, $\mathrm{CV}_{Y}$, if and only if the environmental good and the private consumption good are substitutes (complements) and their point correlation is lower than a weighted ratio of income inequality and environmental inequality, or the environmental good and the private consumption good are complements (substitutes) and their point correlation is higher than a weighted ratio of income inequality and environmental inequality.

$$
\frac{\partial \mu_{\mathrm{WTP}}\left(\mu_{Y}, \mathrm{CV}_{Y}, \mu_{E}, \mathrm{CV}_{E}, \rho\right)}{\partial \mathrm{CV}_{Y}} \lesseqgtr 0 \text { if and only if }\left\{\begin{array}{l}
\theta>1, \rho<a \text { or } \theta<1, \rho>a \\
\theta=1 \text { or } \rho=a \\
\theta<1, \rho<a \text { or } \theta>1, \rho>a
\end{array},\right.
$$

where $a:=\sqrt{\frac{\ln \left(1+\mathrm{CV}_{Y}^{2}\right)}{\ln \left(1+\mathrm{CV}_{E}^{2}\right)}}$ and $\rho \neq 0$.

Proof See Appendix 1.3.

Proposition 1 states that the effect of income inequality on mean WTP is determined both by whether the environmental good is a substitute for or a complement to the manufactured consumption good and by the correlation of environmental good endowment and income in the society. Compared to the case of homogeneously distributed public goods, which is a special case in my analysis, the latter is an additional determinant for heterogeneously distributed public goods. It shows that the key result of Baumgärtner et al. (2017a) that mean WTP for environmental goods decreases (increases) with income inequality if 
and only if the environmental good and the private consumption good are substitutes (complements) applies only to heterogeneously distributed public goods when the correlation with income is lower than a weighted ratio of income inequality and environmental inequality, $\rho<a$. For cases where the correlation between income and the environmental good is strongly positive, $\rho>a$, the reverse might be true: mean WTP increases (decreases) with income inequality if and only if the environmental good and the private consumption good are substitutes (complements).

The threshold $a$ thereby captures how unequal a society's income distribution is relative to the provision of environmental goods. The parameter $a$ is above unity when income inequality is relatively larger, $\mathrm{CV}_{Y}>\mathrm{CV}_{E}$, but below unity when environmental inequality is relatively larger, $\mathrm{CV}_{Y}<\mathrm{CV}_{E}$. I will now briefly discuss both cases in turn.

First, if income inequality is weakly greater than environmental inequality, $\mathrm{CV}_{Y} \geq \mathrm{CV}_{E}$, it follows directly that $\rho<1 \leq a$ as $\rho \in(-1,1)$. Thus for income inequality being weakly greater than environmental inequality, $\mathrm{CV}_{Y} \geq \mathrm{CV}_{E}$-as for homogeneously distributed public goods - mean WTP always decreases (increases) with income inequality for substitutes (complements). Second, for the case of income inequality being lower than environmental inequality, $\mathrm{CV}_{Y}<\mathrm{CV}_{E}$, the effect of income inequality depends on the correlation, $\rho$. When poorer households are endowed with a comparably high level of the environmental good $\rho<0$, then it generally holds that $\rho<0<a$ as $a>0$. Thus, also if income and environmental good provision are negatively correlated, $\rho<0$, the effect of income inequality on mean WTP is as above. Only in the case of the environmental good being distributed more unequally than income $\mathrm{CV}_{Y}<\mathrm{CV}_{E}$ and richer households enjoying comparably high levels of the environmental good $\rho>a>0$ can the effect of income inequality become the reverse. Note that the more unequal the provision of environmental goods relative to the distribution of income, the lower $a$ becomes and the less strongly positive the correlation, $\rho$, needs to be to end up in the case where societal WTP goods increases (decreases) with income inequality for substitutes (complements).

The rationale behind the reverse effect of income inequality on mean WTP in the case of a strongly positive correlation and relatively high environmental inequality is as follows: A decrease in income inequality means that at least one of the poorer households is better off, while at least one of the richer households is worse off and mean income in the society remains unchanged. This has two opposing effects. First, the environmental good being a substitute for consumption goods is equivalent to an income elasticity of WTP being below unity, i.e. richer households are willing to pay a smaller share of their income than poorer households for the environmental good. A reduction of income inequality therefore increases mean WTP, as the gains in WTP of the poorer household overcompensate for the losses in WTP of the richer household. Second, a positive correlation between income and the environmental good means that households with higher incomes enjoy more of the environmental good than households with lower incomes. For substitutes, a higher endowment with the environmental good contributes to a higher WTP, and thus for a positive correlation, to a higher WTP of richer households relative to their income. Through this second channel of the 'environmental-endowment-income-correlation' effect, reducing income inequality decreases mean WTP. Hence, in cases where the environmental good provision is more unequal than the distribution of income, the second effect might outweigh the first if the correlation between income and environmental good provision is sufficiently strong. 
Question 2 How does environmental inequality affect society's mean WTP for the environmental good?

Proposition 2 Mean WTP for the environmental good, $\mu_{\mathrm{WTP}}$, decreases (increases) with relative environmental inequality, $\mathrm{CV}_{E}$, if and only if the environmental good and the private consumption good are substitutes (complements) and their point correlation is lower than a weighted ratio of environmental and income inequality, or the environmental good and the private consumption good are complements (substitutes) and their point correlation is larger than a negative weighted ratio of environmental and income inequality.

$$
\frac{\partial \mu_{\mathrm{WTP}}\left(\mu_{Y}, \mathrm{CV}_{Y}, \mu_{E}, \mathrm{CV}_{E}, \rho\right)}{\partial \mathrm{CV}_{E}} \lesseqgtr 0 \text { if and only if }\left\{\begin{array}{l}
\theta>1, \rho<b \text { or } \theta<1, \rho>b \\
\theta=1 \text { or } \rho=b \\
\theta<1, \rho<b \text { or } \theta>1, \rho>b
\end{array},\right.
$$

where $b:=\sqrt{\frac{\ln \left(1+\mathrm{CV}_{E}^{2}\right)}{\ln \left(1+\mathrm{CV}_{Y}{ }^{2}\right)}}=a^{-1}$ and $\rho \neq 0$.

Proof See Appendix 1.4.

Proposition 2 depicts that for heterogenously distributed environmental goods, environmental inequality has a similar effect on mean WTP as income inequality. The effect of environmental inequality on the mean WTP is determined both by whether the environmental good is a substitute for or complement to manufactured consumption goods and by how the correlation between environmental goods and income in the population of households, $\rho$, is related to the extent of environmental inequality relative to income inequality, $b$.

The logic behind the effect of environmental inequality on mean WTP is as follows. For the case of substitutes, $\theta \in(1, \infty)$, which is for CES preferences analogous to an income elasticity of WTP below unity, $\eta \in(0,1)$, individual WTP increases with environmental good endowment $E_{i}$, but at a decreasing rate [see Eq. (4)]. Thus, households that enjoy less of the environmental good ('environmentally poor' households) have a relatively higher WTP than households that enjoy more of the environmental good ('environmentally rich' households). A more equitable environmental good provision implies that at least one environmentally poor household faces an increase in environmental good endowment, while at least one environmentally rich household faces a decrease. As a result, the gains in WTP of environmentally poor households exceed the losses in WTP of environmentally rich households so that society's mean WTP for the environmental good increases.

When the provision of environmental goods in society is not independent of income, the effect of environmental inequality also depends on their correlation, $\rho$, relative to a weighted ratio of environmental inequality and income inequality, $b$. For environmental inequality weakly greater than income inequality, $\mathrm{CV}_{E} \geq \mathrm{CV}_{Y}$, the condition $\rho<b$ is generally fulfilled as $b>1>\rho$. It also follows directly for a negative correlation, $\rho<0$, that $\rho<0<b$ as $b>0$. Thus, Proposition 2 states that in societies where environmental inequality is higher than income inequality or where the correlation between income and environmental good provision is negative, mean WTP decreases (increases) with environmental inequality if and only if the environmental good is a substitute for (complement to) manufactured consumption goods. The effect of environmental inequality is reverse for cases of environmental inequality lower than income inequality and a 
positive correlation of income and environmental good provision, if only if the correlation is stronger than a weighted ratio of environmental and income inequality.

Table 1 summarizes the cases in Propositions 1 and 2, on how income inequality or environmental inequality affect societal WTP. In most cases, mean WTP increases (decreases) with either inequality for substitutes (complements). A necessary, but not sufficient, condition for the effect to reverse is a positive correlation, i.e. that income rich household are endowed with more of the environmental good than the poor. The sufficient condition for the effect of income inequality (environmental inequality) to reverse, is that the correlation is stronger than a threshold value given by a weighted ratio of income inequality and environmental inequality (environmental inequality and income inequality).

The symmetry in the effects of a marginal change in both inequalities on societal WTP is already visible in Eq. (10). While for societal WTP the distribution of income and the environmental good play different roles with regard to their mean values, they are perfectly symmetric regarding their CVs. This is because individual WTP, Eq. (4), is a convex (concave) function in both income and the environmental good if and only if the environmental good is a substitute (complement). Jensen's inequality implies, that any many preserving spread - like the log-normal distributions assumed here-in income or the environmental good increases (decrease) the sum of individual WTP - and hence mean WTP - if and only if the environmental good is a substitute (complement).

For the special case, where income and environmental good endowment are distributed independently, Propositions 1 and Propositions 2 simplify.

Corollary 1 (E and Y distributed independently) In case of the environmental good and income being distributed independently $(\rho=0)$, mean WTP for the environmental good, $\mu_{\mathrm{WTP}}^{\text {ind }}(E q .(11))$,

1. decreases (increases) with relative income inequality, $\mathrm{CV}_{Y}$, if and only if the environmental good is a substitute (complement):

$$
\frac{\partial \mu_{\mathrm{WTP}}^{\mathrm{ind}}\left(\mu_{Y}, \mathrm{CV}_{Y}, \mu_{E}, \mathrm{CV}_{E}\right)}{\partial \mathrm{CV}_{Y}} \lesseqgtr 0 \text { if and only if } \theta \gtreqless 1 \text {; }
$$

2. decreases (increases) with relative environmental inequality, $\mathrm{CV}_{E}$, if and only if the environmental good is a substitute (complement):

$$
\frac{\partial \mu_{\mathrm{WTP}}^{\mathrm{ind}}\left(\mu_{Y}, \mathrm{CV}_{Y}, \mu_{E}, \mathrm{CV}_{E}\right)}{\partial \mathrm{CV}_{Y}} \lesseqgtr 0 \text { if and only if } \theta \gtreqless 1 \text {. }
$$

Proof See Appendix 1.5.

Corollary 1 shows that for the case of environmental goods uncorrelated with income, the effect of environmental inequality on mean WTP, $\mu_{\mathrm{WTP}}^{\text {ind }}$, is the same as of income inequality.

Question 3 How does the correlation between income and environmental good endowment affects society's mean WTP? 
Table 1 Effect of inequalities on societal WTP depending on relative magnitudes and correlation, $\rho$. (Color figure online)

\begin{tabular}{cc|c|c|c}
\hline \hline & \multicolumn{2}{c|}{$\mathrm{CV}_{Y}>\mathrm{CV}_{E}$} & \multicolumn{2}{c}{$\mathrm{CV}_{Y}<\mathrm{CV}_{E}$} \\
\cline { 2 - 5 } & $\rho>0$ & $\rho<0$ & $\rho>0$ & $\rho<0$ \\
\hline Substitutes $(\theta>1)$ & $\downarrow(\uparrow)$ & $\downarrow \downarrow$ & $(\uparrow) \downarrow$ & $\downarrow \downarrow$ \\
Complements $(\theta<1)$ & $\uparrow(\downarrow)$ & $\uparrow \uparrow$ & $(\downarrow) \uparrow$ & $\uparrow \uparrow$ \\
\hline
\end{tabular}

Upward (downward) arrows indicate a positive (negative) effect of inequality on societal WTP. Blue colour refers to income inequality, $\mathrm{CV}_{Y}$, green to environmental inequality, $\mathrm{CV}_{E}$

Next, I study how a change in the correlation between environmental good endowment and income, $\rho$, affects societal WTP, $\mu_{\mathrm{WTP}}$. A change in $\rho$ might result from an environmental policy altering the spatial distribution of environmental amenities. This could be, for instance, the loss of environmental quality and equivalent compensation or offsetting of this loss at a near site required by an environmental impact assessment.

A further, more indirect, interpretation of a change in $\rho$, could be households adapting their location to the spatial distribution of environmental goods ('sorting'). Household sorting will generally change how income and endowment with the environmental good is correlated within society. Richer (poorer) households moving to places where environmental quality is high will increase (decrease) the correlation, $\rho$, between income and environmental good endowment. The effect of sorting on societal WTP can thus indirectly be studied via its effect on $\rho .^{11}$

Proposition 3 Mean WTP for the environmental good, $\mu_{\mathrm{WTP}}$, increases (decreases) with the correlation between income and environmental good endowment in society, $\rho$, if and only if the environmental good and the private consumption good are substitutes (complements).

$$
\frac{\partial \mu_{\mathrm{WTP}}\left(\mu_{Y}, \mathrm{CV}_{Y}, \mu_{E}, \mathrm{CV}_{E}, \rho\right)}{\partial \rho} \gtreqless 0 \text { if and only if } \theta \gtreqless 1 \text {. }
$$

Proof See Appendix 1.7.

Proposition 3 shows that the way an increase in the correlation between income and environmental good endowment, $\rho$, affects societal WTP, $\mu_{\mathrm{WTP}}$, is determined by the substitutability between private consumption goods and the environmental good, $\theta$. An increase in $\rho$ reinforces societal WTP for the environmental good for the case of substitutes, but decreases societal WTP in the case of complements. For instances where household sorting increases the correlation of environmental good endowment and income, $\rho$, it

\footnotetext{
11 I sketch in "Appendix 1.6" for a simple case of two income groups and CES preferences that in a situation where neighborhood sorting arises only from differences in the endowment with the environmental good, households with higher incomes will sort into places with higher environmental quality. In such a situation, sorting increases the correlation between income and environmental good endowment, $\rho$. This finding mirrors the well-established results from equilibrium sorting models, that when households differ only along one dimension, such as income, residential sorting results in perfectly stratified households along this dimension (Epple and Romer 1991; Epple and Platt 1998; Kuminoff et al. 2013).
} 
will thus indirectly increase (decrease) societal WTP for the environmental good if this is a substitute for (complement to) manufactured consumption goods.

This result can be explained as follows. All else equal, an increase in $\rho$ means that at least one relatively income rich household experiences a higher environmental good endowment, while at least one poorer household experiences a decrease. Moreover, observe from Eq. (4) that the cross-derivate of individual WTP with respect to environmental good endowment and income, $\frac{\mathrm{WTP}}{\partial E_{i}, \partial Y_{i}}$, is positive (negative) if and only if the environmental good is a substitute (complement). Thus, in case of substitutes societal WTP increases with a higher correlation, as the increase in the rich households' total WTP for an increase $E_{i}$, overcompensates loss in WTP of the poor.

\subsection{Benefit Transfer and Heterogeneously Distributed Environmental Goods}

Next, I derive structural transfer factors to account for differences in the distribution of the endowment with the environmental good and income. These transfer factors can be used to adjust WTP estimates from primary valuation studies to inform environmental policy and management in other contexts, as well as to adjust for the socially desired distribution. In benefit transfer, WTP estimates from a valuation study conducted in one context $s$ the 'study' site-inform policy making in other context $p$ - the 'policy' site. Based on the model set-up presented above, I specify the benefit transfer function approach (e.g. Loomis 1992) for heterogeneously distributed environmental goods.

Proposition 4 Assume households' preferences $(\theta, \alpha)$ are identical at study site $s$ and policy site $p$. If at the study site mean WTP for the environmental good is $\mu_{\mathrm{WTP}}^{\mathrm{s}}$ (Eq. 10), the market price level for consumption goods is $P^{\mathrm{s}}$, mean income is $\mu_{Y}^{\mathrm{s}}$, relative income inequality is $\mathrm{CV}_{Y}^{\mathrm{s}}$, the mean quantity of the environmental good is $\mu_{E}^{\mathrm{s}}$, the relative environmental inequality is $\mathrm{CV}_{E}^{\mathrm{s}}$ and the correlation between income and the environmental good is $\rho^{\mathrm{s}}$, then at the policy site with $\left(P^{\mathrm{p}}, \mu_{Y}^{\mathrm{p}}, \mathrm{CV}_{Y}^{\mathrm{p}}, \mu_{E}^{\mathrm{p}}, \mathrm{CV}_{E}^{\mathrm{p}}, \rho^{\mathrm{p}}\right)$ the mean WTP is given as

$$
\mu_{\mathrm{WTP}}^{\mathrm{p}}=\mathcal{T}\left(P^{\mathrm{p}}, \mu_{Y}^{\mathrm{p}}, \mathrm{CV}_{Y}^{\mathrm{p}}, \mu_{E}^{\mathrm{p}}, \mathrm{CV}_{E}^{\mathrm{p}}, \rho^{\mathrm{p}} ; P^{\mathrm{s}}, \mu_{Y}^{\mathrm{s}}, \mathrm{CV}_{Y}^{\mathrm{s}}, \mu_{E}^{\mathrm{s}}, \mathrm{CV}_{E}^{\mathrm{s}}, \rho^{s}\right) \cdot \mu_{\mathrm{WTP}}^{\mathrm{s}},
$$

where the transfer function $\mathcal{T}()$ factorizes into the following transfer factors

$$
\begin{aligned}
& \mathcal{T}\left(P^{\mathrm{p}}, \mu_{Y}^{\mathrm{p}}, \mathrm{CV}_{Y}^{\mathrm{p}}, \mu_{E}^{\mathrm{p}}, \mathrm{CV}_{E}^{\mathrm{p}}, \rho^{\mathrm{p}} ; P^{\mathrm{s}}, \mu_{Y}^{\mathrm{s}}, \mathrm{CV}_{Y}^{\mathrm{s}}, \mu_{E}^{\mathrm{s}}, \mathrm{CV}_{E}^{\mathrm{s}}, \rho^{s}\right) \\
& \quad=\mathcal{T}_{P}\left(P^{\mathrm{p}}, P^{\mathrm{s}}\right) \cdot \mathcal{T}_{\mu_{Y}}\left(\mu_{Y}^{\mathrm{p}}, \mu_{Y}^{\mathrm{s}}\right) \cdot \mathcal{T}_{\mu_{E}}\left(\mu_{E}^{\mathrm{p}}, \mu_{E}^{\mathrm{s}}\right) \cdot \mathcal{T}_{\mathrm{CV}_{Y}, \mathrm{CV}_{E}, \rho}\left(\mathrm{CV}_{Y}^{\mathrm{p}}, \mathrm{CV}_{E}^{\mathrm{p}}, \rho^{\mathrm{p}}, \mathrm{CV}_{Y}^{\mathrm{s}}, \mathrm{CV}_{E}^{\mathrm{s}}, \rho^{\mathrm{s}}\right),
\end{aligned}
$$

with

$$
\begin{gathered}
\mathcal{T}_{P}\left(P^{\mathrm{p}}, P^{\mathrm{s}}\right)=\left(\frac{P^{\mathrm{p}}}{P^{\mathrm{s}}}\right)^{\frac{\theta-1}{\theta}}, \\
\mathcal{T}_{\mu_{Y}}\left(\mu_{Y}^{\mathrm{p}}, \mu_{Y}^{\mathrm{s}}\right)=\left(\frac{\mu_{Y}^{\mathrm{p}}}{\mu_{Y}^{\mathrm{s}}}\right)^{\frac{1}{\theta}},
\end{gathered}
$$




$$
\begin{gathered}
\mathcal{T}_{\mu_{E}}\left(\mu_{E}^{\mathrm{p}}, \mu_{E}^{\mathrm{s}}\right)=\left(\frac{\mu_{E}^{\mathrm{p}}}{\mu_{E}^{\mathrm{s}}}\right)^{\frac{\theta-1}{\theta}} \\
\mathcal{T}_{\mathrm{CV}_{Y}, \mathrm{CV}_{E}, \rho}\left(\mathrm{CV}_{Y}^{\mathrm{p}}, \mathrm{CV}_{E}^{\mathrm{p}}, \rho^{\mathrm{p}}, \mathrm{CV}_{Y}^{\mathrm{s}}, \mathrm{CV}_{E}^{\mathrm{s}}, \rho^{\mathrm{s}}\right)=\left(\frac{1+\mathrm{CV}_{Y}^{\mathrm{p} 2}}{1+\mathrm{CV}_{Y}^{\mathrm{s} 2}}\right)^{\frac{1-\theta}{2 \theta^{2}}} \cdot\left(\frac{1+\mathrm{CV}_{E}^{\mathrm{p} 2}}{1+\mathrm{CV}_{E}^{\mathrm{s} 2}}\right)^{\frac{1-\theta}{2 \theta^{2}}} \\
\cdot \exp \left[\frac{\theta-1}{\theta^{2}}\left(\rho^{\mathrm{p}} \sqrt{\ln \left(1+\mathrm{CV}_{Y}^{\mathrm{p}}\right) \ln \left(1+\mathrm{CV}_{E}^{\mathrm{p} 2}\right)}-\rho^{\mathrm{s}} \sqrt{\ln \left(1+\mathrm{CV}_{Y}^{\mathrm{s}} 2\right) \ln \left(1+\mathrm{CV}_{E}^{\mathrm{s} 2}\right)}\right)\right] .
\end{gathered}
$$

Proof See Appendix 1.8.

Proposition 4 shows how to control for differences in income inequality, environmental inequality and the correlation of income and environmental good endowment by using a closed-form transfer factor $\mathcal{T}_{\mathrm{CV}_{Y}, \mathrm{CV}_{E}, \rho}$. The transfer factor $\mathcal{T}_{\mathrm{CV}_{Y}, \mathrm{CV}_{E}, \rho}$ captures the dynamics studied in Proposition 1-3. It is thus not surprising that $\mathcal{T}_{\mathrm{CV}_{Y}, \mathrm{CV}_{E}, \rho}$ can be greater or smaller than unity-implying a downward or upward adjustment of societal WTP-depending on whether income and the environmental good are distributed more equally at the study site or at the policy site, whether the income and the environmental good are more strongly correlated at the policy or at the study site, and whether the environmental good is a substitute for or complement to manufactured consumption goods. Note that for $\theta=1$, no adjustment is necessary, $\mathcal{T}_{\mathrm{CV}_{Y}, \mathrm{CV}_{E}, \rho}=1$.

For $E$ and $Y$ being distributed independently $(\rho=0)$ at both sites, the transfer factor for inequalities $\mathcal{T}_{\mathrm{CV}_{Y}, \mathrm{CV}_{E}, \rho}$, Eq. (22), simplifies to two disentangled transfer factors for income inequality and environmental inequality (Appendix 1.8):

$$
\begin{gathered}
\mathcal{T}_{\mathrm{CV}_{Y}, \mathrm{CV}_{E}}\left(\mathrm{CV}_{Y}^{\mathrm{p}}, \mathrm{CV}_{E}^{\mathrm{p}}, \mathrm{CV}_{Y}^{\mathrm{s}}, \mathrm{CV}_{E}^{\mathrm{s}}\right)=\left(\frac{1+\mathrm{CV}_{Y}^{\mathrm{p} 2}}{1+\mathrm{CV}_{Y}^{\mathrm{s} 2}}\right)^{\frac{1-\theta}{2 \theta^{2}}} \cdot\left(\frac{1+\mathrm{CV}_{E}^{\mathrm{p} 2}}{1+\mathrm{CV}_{E}^{\mathrm{s} 2}}\right)^{\frac{1-\theta}{2 \theta^{2}}} \\
=: \mathcal{T}_{\mathrm{CV}_{Y}}\left(\mathrm{CV}_{Y}^{\mathrm{p}}, \mathrm{CV}_{Y}^{\mathrm{s}}\right) \cdot \mathcal{T}_{\mathrm{CV}_{E}}\left(\mathrm{CV}_{E}^{\mathrm{p}}, \mathrm{CV}_{E}^{\mathrm{s}}\right)
\end{gathered}
$$

Note that as $\mathcal{T}_{\mathrm{CV}_{Y}, \mathrm{CV}_{E}}$ factorizes into two variable-specific factors, one can correct for differences in $\mathrm{CV}_{Y}$ or $\mathrm{CV}_{E}$ separately and without paying attention to the other type of inequality. In this case the transfer factors for environmental inequality is absolute analogue to the one for income inequality.

\section{Empirical Application}

Next I illustrate empirical magnitudes for a case study on forest preservation in Poland. This application serves the purpose of assessing whether the argument developed above is associated with considerable economic effect sizes that warrant the actual use of the novel benefit transfer factor, $\mathcal{T}_{\mathrm{CV}_{Y}, \mathrm{CV}_{E}, \rho}$, in public policy making. I draw on a valuation study offering a unique case for illustration, as WTP was elicited for a single national environmental good ('Polish ecologically-valuable forest'), the access to which differs in society ('proximity to the next forest') and substantially affects households' WTPs. 
Forests are subject to high rates of degradation and deforestation globally. Until the late nineteenth century, deforestation was most pronounced in the temperate climate zone, where recent decades have seen net gains in forest area (FAO 2016). Forests serve crucial ecological functions such as carbon sequestration, water purification, and soil conservation, and offer habitats for a variety of wildlife (FAO 2016). They contribute substantially to human well-being (SCBD 2001), with forest ecosystem services encompassing a range of use values, such as timber supply and opportunities for recreation, as well as non-use values, such as the existence values of various rare flora and fauna. A forest's actual array of ecosystem services depends on the management regime and varies from heavily economically used forests, which are associated with high timber production but little biodiversity and recreational value, to pristine forests, which are associated with very little timber production but high biodiversity and recreational value (SCBD 2001). People live in different proximities to forests, which is likely to result in an unequal distribution of forest ecosystem services, such as recreational values. Thus, forests are an example for environmental public goods, where endowment is heterogeneous.

Polish forests are among the largest and most valuable forests in Europe. 29.3\% of Poland's land area is covered by forest, including the Bialawiza forest, which is commonly referred to as the last lowland forest in temperate Europe with primeval fragments (Government of Poland 2014). Overall, 65\% of Poland's biodiversity resources and 50\% of Poland's Natura 2000 sites are situated in forests (Czajkowski et al. 2009; Government of Poland 2014). Approximately $3 \%$ of Poland's $90,000 \mathrm{~km}^{2}$ total forest area is considered to be highly ecologically valuable, as it is still in almost pristine condition. Only half of this forest area is under effective nature protection (Czajkowski et al. 2017). The remaining half is under pressure from human use and exploited as regular economically used forests (Czajkowski et al. 2014a).

To investigate the relationship between the distribution of forest ecosystem services and income and the societal WTP for forest protection, I draw on survey and forest data studied in depth by Budziński et al. (2018) and Czajkowski et al. (2014a, b, 2017). Respondents were asked for their willingness to pay for an increase in national income taxes for different national forest management options, including protecting all of Poland's most ecologically valuable forests (3\% of the Polish forest area). ${ }^{12}$ The survey was carried out on a representative sample of 1001 Polish adults in January 2010 employing face-to-face computerassisted interviews. To ensure representativeness, a multi-stage sampling strategy was applied, randomly selecting first communities and then adult household members. Survey data included respondents' household income and ZIP codes. Additionally data on forest characteristics at a high spatial resolution were obtained from the European Environmental Agency's CORINE Land Cover dataset and the Polish Information System of State Forests and aggregated on $10 \times 10 \mathrm{~km}^{2}$ grid squares. ${ }^{13}$

A subset of $N=714$ respondents also provided information on their monthly net household income [in 2011-PLN], defining the sample used in the following. Income, $Y_{i}$, is distributed with a mean of $\mu_{Y}^{\mathrm{s}}=2758$ and a standard deviation of $\sigma_{Y}^{\mathrm{s}}=1857$, corresponding

\footnotetext{
12 Respondents were informed that forest protection would mean prohibiting any human interference except recreational use.

13 For further details on the survey design, see Czajkowski et al. (2014a), and on forest data, see Czajkowski et al. (2017).
} 
to a relative income inequality of $\mathrm{CV}_{Y}^{s}=0.66$. With this, the sample's relative income inequality is slightly below the national average according to official statistics. ${ }^{14}$

I use a household's forest proximity as a proxy for the endowment with forest ecosystem services, $E_{i}$. Forest proximity is measured as the inverse of the average Euclidean distance from any point in a respondent's $10 \times 10 \mathrm{~km}^{2}$ grid square to the nearest forest (independent of it ecological value) within this grid square (Czajkowski et al. 2017). Proximity is chosen as a proxy for the endowment with forest ecosystem services as it has the strongest effect on WTP for forest protection among different forest characteristics-such as area of coniferous forest, deciduous forest, mixed forest, old or particularly biodiverse forest-with larger distances substantially reducing WTP for forest protection (Czajkowski et al. 2017). The coefficient of variation of households' forest proximity is $\mathrm{CV}_{E}^{\mathrm{s}}=0.57$. Thus, forest proximity is more equally distributed than income in Poland. The correlation between respondents' forest proximity, $E_{i}$, and household income, $Y_{i}$, is $\rho^{\mathrm{s}}=-0.1{ }^{15}$ Thus, richer households tend to live further away from forests in Poland. ${ }^{16}$ The average distance to the nearest forest, the location of respondents, and their household income is depicted in Fig. 1. Histograms on the distribution of $Y_{i}$ and $E_{i}$ are depicted in Appendix 1.11.

I complement these data from Czajkowski et al. (2017) with a parameter range for the elasticities of substitution, $\theta$, found in two global meta-studies. ${ }^{17}$ Thereby I infer $\theta$ indirectly from the income elasticities of WTP, $\eta$, as elicited in recent valuation studies. As a best guess estimate, I take the income elasticity of WTP for forest ecosystem services from Chiabai et al. (2011), who provide a global meta-study on forest ecosystem services encompassing 86 WTP estimates from 27 valuation studies. They estimate an income elasticity of WTP for forest recreation of $\eta=0.63$ and for non-use forest ecosystem services of $\eta=0.75$. As the forest preservation under question would allow for recreational use, I take the arithmetic mean of both elasticities and derive as its inverse the elasticity of substitution between non-consumptive forest ecosystem services and manufactured consumption goods, $\theta^{\text {forest }}=\left(\frac{0.63+0.75}{2}\right)^{-1}=1.46 .{ }^{18}$ Additionally I take a range of elasticities of substitution from Drupp (2018), who reviews existing empirical estimates for the income elasticity of WTP from contingent valuation studies since 2000 for different ecosystems and services to indirectly asses $\theta$, finding a range from $\theta^{\min }=0.86$ to $\theta^{\max }=7.14 .^{19}$ I use these three

14 The World Bank estimates a coefficient of variation of disposable household income for Poland of $\mathrm{CV}_{Y}^{\mathrm{POL}}=0.69$ (Zaidi 2009), based on data from the 2006 European Union Survey of Income and Living Conditions. In a contingent valuation study on water quality improvement in the Baltic Sea conducted in 2011, a representative sample of Polish respondents exhibited exactly the same coefficient of variation of their monthly disposable income (Meya et al. 2018).

15 The correlation coefficient $\rho$ is significant at the $p<0.01$ level.

16 "Appendix 1.6" shows that if locations differ only in environmental good provision then spatial sorting will result in richer households living where environmental quality is high, e.g. $\rho>0$. However, in general locations differ along several other dimensions, such as the availability of jobs, which might be relatively more important for residence choice.

17 The use of an elasticity of substitution from meta-studies is in line with the model assumption that people have identical preferences. While I only aim at illustrating ranges, I admit that these general measures for the elasticity of substitution will most likely not be a precise estimate for the population and ecosystem service under consideration, but might arguably be more accurate for a policy site.

18 Remarkably, this is close to an income elasticity elicited for another environmental good in the same region. Czajkowski and Scasny (2010) find an income elasticity of WTP of $\eta=0.64$, corresponding to an elasticity of substitution of $\theta=1.56$, for lake water quality improvements in Poland and the Czech Republic.

19 Drupp (2018) finds a mean of $\theta^{E S}=2.31$ across all kinds of ecosystem services, which implies a slightly larger degree of substitutability than I assume here for forest ecosystem services based on Chiabai et al. (2011). 
estimates to explore the effect of different degrees of substitutability between forest ecosystem services and manufactured consumption goods. All parameter inputs are summarized in Table 2.

I now study how my model predicts societal WTP for forest protection to change if households were more (un)equal in their proximity to forests, if household income were distributed more (un)equally, or if forest proximity were more strongly negatively (positively) correlated with income. To this end, I specify the transfer factor $\mathcal{T}_{\mathrm{CV}_{Y}, \mathrm{CV}_{E}, \rho}$ [Eq. (22)] with the parameters in Table 2 for different hypothetical choices of $\mathrm{CV}_{Y}^{\mathrm{p}}, \mathrm{CV}_{E}^{\mathrm{p}}$ and $\rho^{\mathrm{p}} .{ }^{20}$

The resulting WTP adjustments are considerable (Table 3). Hypothetically reducing environmental inequality to zero, $\mathcal{T}_{\mathrm{CV}_{Y}, \mathrm{CV}_{E}, \rho}\left(\mathrm{CV}_{Y}^{\mathrm{s}}, 0,0, \mathrm{CV}_{Y}^{\mathrm{s}}, \mathrm{CV}_{E}^{\mathrm{s}}, \rho^{\mathrm{s}}\right)$, would increase mean WTP by $4 \%$. As income inequality is larger in the status quo, reducing it to zero, $\mathcal{T}_{\mathrm{CV}_{Y}, \mathrm{CV}_{E}, \rho}\left(0, \mathrm{CV}_{E}^{\mathrm{s}}, 0, \mathrm{CV}_{Y}^{\mathrm{s}}, \mathrm{CV}_{E}^{\mathrm{s}}, \rho^{\mathrm{s}}\right)$, would imply a slightly higher upward adjustment of WTP by $5 \%$. Adjusting for the even more extreme situation with an equal distribution of forest proximity and income, $\mathcal{T}_{\mathrm{CV}_{Y}, \mathrm{CV}_{E}, \rho}\left(0,0,0, \mathrm{CV}_{Y}^{\mathrm{s}}, \mathrm{CV}_{E}^{\mathrm{s}}, \rho^{\mathrm{s}}\right)$, societal WTP for forest protection would be $8 \%$ higher. If forest ecosystem services were complements, $\theta^{\text {min }}$, the effect would be reversed, and a complete egalitarian distribution would imply a downward adjustment of societal WTP by $6 \%$.

It is also apparent from comparing $\mathcal{T}_{\mathrm{CV}_{Y}, \mathrm{CV}_{E}, \rho}\left(0,0,0, \mathrm{CV}_{Y}^{\mathrm{s}}, \mathrm{CV}_{E}^{\mathrm{s}}, \rho^{\mathrm{s}}\right)$ for $\theta^{\text {forest }}$ and $\theta^{\max }$ that the required WTP adjustment does not strictly increase or decrease with the degree of substitutability, $\theta$. Figure 2 depicts $\mathcal{T}_{\mathrm{CV}_{Y}, \mathrm{CV}_{E}, \rho}\left(0,0,0, \mathrm{CV}_{Y}^{\mathrm{s}}, \mathrm{CV}_{E}^{\mathrm{s}}, \rho^{\mathrm{s}}\right)$ as a function of $\theta$, which has its maximum value close to the mean elasticity of substitution reviewed by Drupp (2018) for global ecosystem services, $\theta^{\mathrm{ES}}$, and decreases sharply with stronger complementarity, $\theta \rightarrow 0$. Moreover, I find that for a doubling of current environmental inequality or income inequality-implying adjustment factors of $\mathcal{T}_{\mathrm{CV}_{Y}, \mathrm{CV}_{E}, \rho}\left(\mathrm{CV}_{Y}^{\mathrm{s}}, 2 \mathrm{CV}_{E}^{\mathrm{s}}, \rho^{\mathrm{s}}, \mathrm{CV}_{Y}^{\mathrm{s}}, \mathrm{CV}_{E}^{\mathrm{s}}, \rho^{\mathrm{s}}\right)$ or $\mathcal{T}_{\mathrm{CV}_{Y}, \mathrm{CV}_{E}, \rho}\left(2 \mathrm{CV}_{Y}^{\mathrm{s}}, \mathrm{CV}_{E}^{\mathrm{s}}, \rho^{\mathrm{s}}, \mathrm{CV}_{Y}^{\mathrm{s}}, \mathrm{CV}_{E}^{\mathrm{s}}, \rho^{\mathrm{s}}\right)-$ WTP would decrease by $6 \%$ or $7 \%$, respectively. Again, the larger effect of income inequality reflects that income is more unequally distributed in Poland than forest proximity.

Finally, I find that differences in the correlation between environmental good endowment and income can require slightly higher WTP adjustment. All else equal, in a situation where forest proximity and income were positively correlated with a Pearson correlation coefficient of $\rho^{\mathrm{p}}=0.5$ societal WTP would be $6 \%$ higher than elicited in the present study, corresponding to a transfer factor of $\mathcal{T}_{\mathrm{CV}_{Y}, \mathrm{CV}_{E}, \rho}\left(\mathrm{CV}_{Y}^{\mathrm{s}}, \mathrm{CV}_{E}^{\mathrm{s}}, 0.5, \mathrm{CV}_{Y}^{\mathrm{s}}, \mathrm{CV}_{E}^{\mathrm{s}}, \rho^{\mathrm{s}}\right)$. For a high degree of substitutability, this would imply a WTP adjustment of $18 \%$. For complements, $\theta^{\mathrm{min}}$, the case would be the opposite: societal WTP would be lowered by $3 \%$. Figure 5 (Appendix 1.11) illustrates $\mathcal{T}_{\mathrm{CV}_{Y}, \mathrm{CV}_{E}, \rho}\left(\mathrm{CV}_{Y}^{\mathrm{s}}, \mathrm{CV}_{E}^{\mathrm{s}}, \rho^{\mathrm{p}}, \mathrm{CV}_{Y}^{\mathrm{s}}, \mathrm{CV}_{E}^{\mathrm{s}}, \rho^{\mathrm{s}}\right)$ as a function of $\rho^{\mathrm{p}}$ for different degrees of substitutability.

These estimates illustrate the importance of considering the distribution of environmental goods and income when aggregating WTP and in particular when using these aggregate WTPs in benefit transfer or environmental cost-benefit analysis. ${ }^{21}$

\footnotetext{
${ }^{20}$ For $\mathrm{CV}_{Y}^{p}$ or $\mathrm{CV}_{E}^{p}$ equal to zero, i.e. when the standard deviation of $Y$ or $E$ is zero, the correlation coefficient $\rho$ does not exist. I therefore assume independently distributed endowments with the environmental good and income, $\rho=0$, to evaluate these extreme scenarios.

21 As expected, differences in the mean forest proximity and mean income require comparably larger adjustments. For instance, doubling mean forest proximity, $\mathcal{T}_{\mu_{E}}\left(2 \mu_{E}^{\mathrm{s}}, \mu_{E}^{\mathrm{s}}\right)$, would imply an upward adjustment of mean WTP by $24.37 \%$, and doubling mean income, $\mathcal{T}_{\mu_{Y}}\left(2 \mu_{Y}^{\mathrm{s}}, \mu_{Y}^{\mathrm{s}}\right)$, would even imply an upward adjustment of mean WTP by $60.81 \%$.
} 


\section{Legend}

Forest distance [in $\mathrm{m}]$
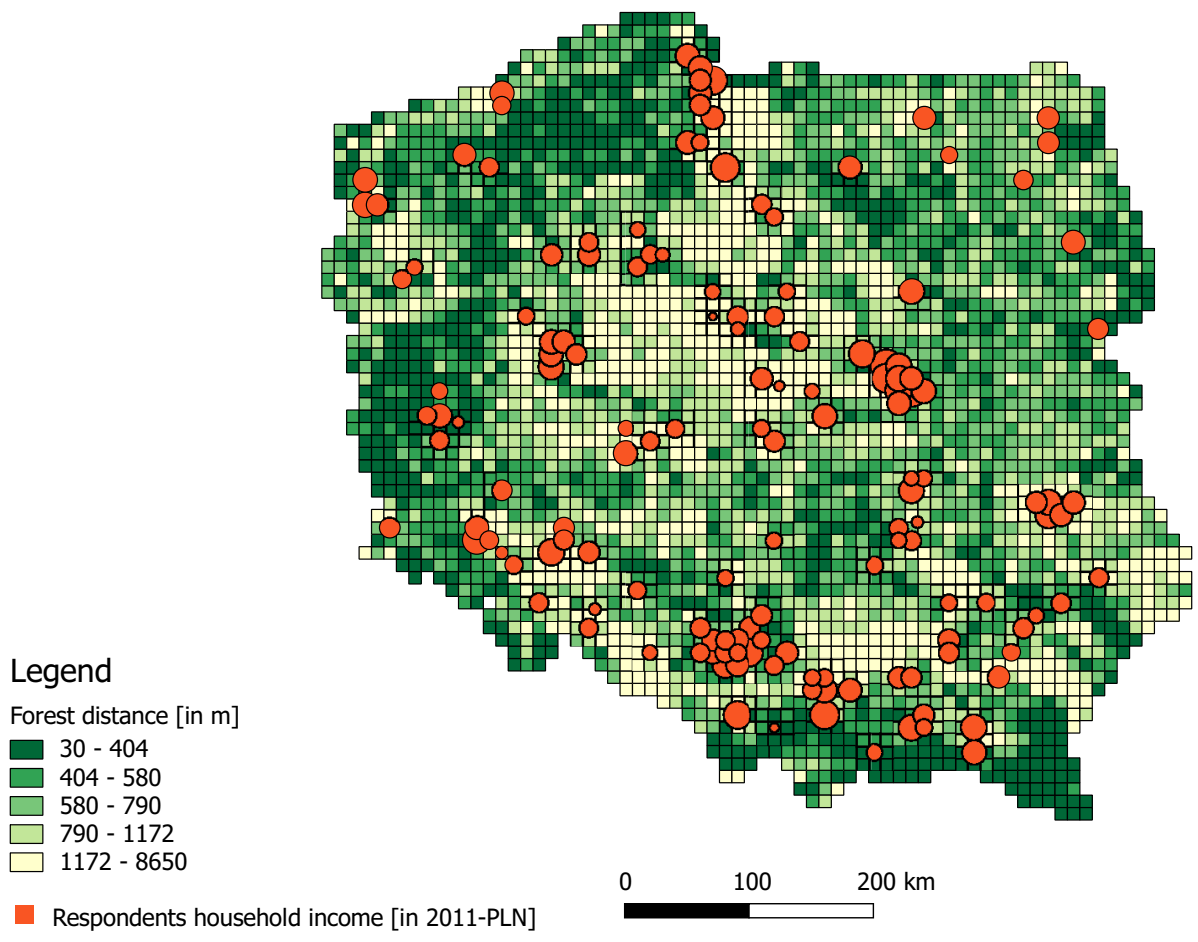

Fig. 1 Spatial distribution of distance to forests in Poland and respondents' income. Circle sizes represent mean household income stated by respondents in the $10 \times 10 \mathrm{~km}^{2}$ grid square of their residency. The average Euclidean distance from each point in a $10 \times 10 \mathrm{~km}^{2}$ grid square to the nearest forest is shown in green

Table 2 Parameter values used in empirical application

\begin{tabular}{|c|c|c|}
\hline Variable & Value & Source \\
\hline elasticity of substitution $\left(\theta^{\text {forest }}\left[\theta^{\min } ; \theta^{\max }\right]\right)$ & $1.46[0.86 ; 7.14]$ & Chiabai et al. (2011) and Drupp (2018) \\
\hline $\begin{array}{l}\text { coefficient of variation of forest proximity } \\
\left(\mathrm{CV}_{E}^{\mathrm{s}}\right)\end{array}$ & 0.57 & $\begin{array}{l}\text { Own calculation based on Czajkowski et al } \\
\text { (2017) }\end{array}$ \\
\hline $\begin{array}{l}\text { coefficient of variation of disposable house- } \\
\text { hold income }\left(\mathrm{CV}_{Y}^{\mathrm{s}}\right)\end{array}$ & 0.66 & Czajkowski et al. (2014a) \\
\hline $\begin{array}{l}\text { correlation of income and forest proxim- } \\
\text { ity }\left(\rho^{\mathrm{s}}\right)\end{array}$ & -0.10 & $\begin{array}{l}\text { Own calculation based on Czajkowski et al } \\
\text { (2017) }\end{array}$ \\
\hline
\end{tabular}

\section{Discussion}

Here I discuss several assumptions made in the analysis and the extent to which these might limit the generality of my results. These assumptions are (1) the absence of household mobility, (2) the purely bio-physical heterogeneity in environmental good endowment, (3) the log-normal distribution of the environmental good, (4) the constant elasticity of substitution preferences (5) the assumption of self-regarding households, and (6) the coefficient of variation as a measure of environmental inequality. 
Table 3 Resulting transfer factors to correct WTP for differences in the distribution of the environmental good and income

\begin{tabular}{llll}
\hline Transfer factor & $\theta^{\text {forest }}=1.46$ & $\theta^{\min }=0.86$ & $\theta^{\max }=7.14$ \\
\hline $\mathcal{T}_{\mathrm{CV}_{Y}, \mathrm{CV}_{E}, \rho}\left(\mathrm{CV}_{Y}^{\mathrm{s}}, 0,0, \mathrm{CV}_{Y}^{\mathrm{s}}, \mathrm{CV}_{E}^{\mathrm{s}}, \rho^{\mathrm{s}}\right)$ & 1.04 & 0.97 & 1.04 \\
$\mathcal{T}_{\mathrm{CV}_{Y}, \mathrm{CV}_{E}, \rho}\left(0, \mathrm{CV}_{E}^{\mathrm{s}}, 0, \mathrm{CV}_{Y}^{\mathrm{s}}, \mathrm{CV}_{E}^{\mathrm{s}}, \rho^{\mathrm{s}}\right)$ & 1.05 & 0.96 & 1.05 \\
$\mathcal{T}_{\mathrm{CV}_{Y}, \mathrm{CV}_{E}, \rho}\left(0,0,0, \mathrm{CV}_{Y}^{\mathrm{s}}, \mathrm{CV}_{E}^{\mathrm{s}}, \rho^{\mathrm{s}}\right)$ & 1.08 & 0.94 & 1.07 \\
$\mathcal{T}_{\mathrm{CV}_{Y}, \mathrm{CV}_{E}, \rho}\left(\mathrm{CV}_{Y}^{\mathrm{s}}, 2 \mathrm{CV}_{E}^{\mathrm{s}}, \rho^{\mathrm{s}}, \mathrm{CV}_{Y}^{\mathrm{s}}, \mathrm{CV}_{E}^{\mathrm{s}}, \rho^{\mathrm{s}}\right)$ & 0.94 & 1.06 & 0.95 \\
$\mathcal{T}_{\mathrm{CV}_{Y}, \mathrm{CV}_{E}, \rho}\left(2 \mathrm{CV}_{Y}^{\mathrm{s}}, \mathrm{CV}_{E}^{\mathrm{s}}, \rho^{\mathrm{s}}, \mathrm{CV}_{Y}^{\mathrm{s}}, \mathrm{CV}_{E}^{\mathrm{s}}, \rho^{\mathrm{s}}\right)$ & 0.93 & 1.07 & 0.94 \\
$\mathcal{T}_{\mathrm{CV}_{Y}, \mathrm{CV}_{E}, \rho}\left(\mathrm{CV}_{Y}^{\mathrm{s}}, \mathrm{CV}_{E}^{\mathrm{s}}, 0, \mathrm{CV}_{Y}^{\mathrm{s}}, \mathrm{CV}_{E}^{\mathrm{s}}, \rho^{\mathrm{s}}\right)$ & 1.01 & 0.99 & 1.03 \\
$\mathcal{T}_{\mathrm{CV}_{Y}, \mathrm{CV}_{E}, \rho}\left(\mathrm{CV}_{Y}^{\mathrm{s}}, \mathrm{CV}_{E}^{\mathrm{s}},-0.5, \mathrm{CV}_{Y}^{\mathrm{s}}, \mathrm{CV}_{E}^{\mathrm{s}}, \rho^{\mathrm{s}}\right)$ & 0.96 & 1.02 & 0.90 \\
$\mathcal{T}_{\mathrm{CV}_{Y}, \mathrm{CV}_{E}, \rho}\left(\mathrm{CV}_{Y}^{\mathrm{s}}, \mathrm{CV}_{E}^{\mathrm{s}}, 0.5, \mathrm{CV}_{Y}^{\mathrm{s}}, \mathrm{CV}_{E}^{\mathrm{s}}, \rho^{\mathrm{s}}\right)$ & 1.06 & 0.97 & 1.18 \\
\hline
\end{tabular}

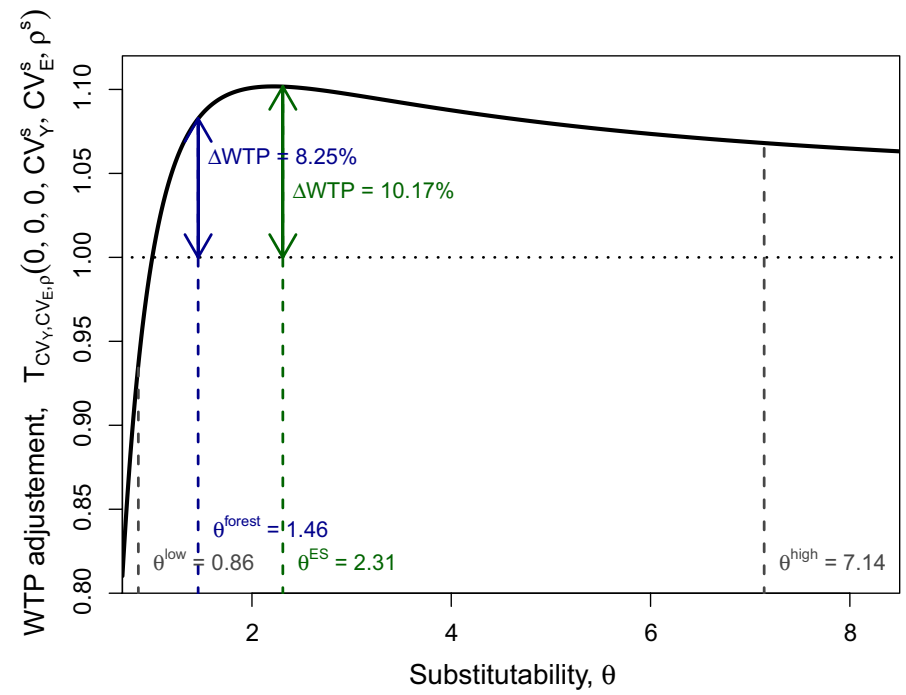

Fig. 2 Relationship between the transfer factor to adjust societal WTP for differences in the distribution of the environmental good and income, $\mathcal{T}_{\mathrm{CV}_{Y}, \mathrm{CV}_{E}, \rho}$, and different degrees of substitutability. In the hypothetical transfer depicted, the societal WTP for forest protection in Poland is adjusted to a situation where proximity to forests and income is distributed equally over the population

First, there is no household mobility and in particular no sorting with respect to environmental quality in the main model. The model framework studied here allows me to evaluate an exogenous change in the joint distribution of environmental good endowment and income, and more importantly to control in benefit transfer for differences in the correlation between income and environmental good endowment between two sites (which are both in sorting equilibrium). However, the model does not anticipate sorting effects induced by a change in the (heterogeneous) distribution of an environmental good. Future research could attempt to explicitly account for sorting by relaxing the assumption of homogeneous preferences building on the new equilibrium sorting models developed by Epple and Platt (1998). The here proposed benefit transfer factors are thus only valid for the evaluation of environmental policies and projects that are 'small' in the sense that the resulting change in the distribution of the environmental good is not large enough to motivate households 
to move. ${ }^{22}$ Turner (2017) makes a first conceptual attempt to account in benefit transfer for the possibility that people and firms change locations in response to a 'large' environmental regulation. Since valuation studies indicate that the income elasticity of WTP is below unity, my model nevertheless suggests that sorting is likely to increase the societal value of environmental goods by changing the correlation between environmental goods and income in society. Whether changes in the specific environmental goods studied in the valuation literature are below or above a level that induces households to move is ultimately an empirical question that remains to be answered in future research.

Second, I studied a heterogeneous distribution of environmental benefits over households in a society arising only from an uneven distribution of biophysical quantities, ${ }^{23}$ but there are other sources of heterogeneity in environmental benefits. In particular, an uneven distribution of benefits might result from heterogeneous preferences regarding the environmental good or because vulnerability-for example, measured as 'dose-response functions'-differs across groups within a society (Hsiang et al. 2019). Moreover, it seems plausible that both preferences regarding the environment and dose-response functions differ across income groups. For instance, Di et al. (2017) find that the effect of air pollution on health is more pronounced for low-income groups. However, there is little empirical research to date how these sources of heterogeneity relate to income. ${ }^{24}$ Furthermore, empirical measurement of biophysical environmental good endowment is already challenging (Hsiang et al. 2019). For simplicity and applicability, I therefore stick to the simplest case of heterogeneity in the physical endowment with environmental goods and leave other sources of heterogeneity as an issue for future research.

Third, I approximated the distribution of the environmental good by a log-normal distribution. It is necessary to assume a specific distributional form in order to derive closed-form solutions and to develop parameterized adjustment factors for benefit transfer. Employing a continuous representation extends upon the previous dichotomous representations in stylized two-region models in the sorting literature. The assumption of log-normality is certainly only a first approximation, and its empirical fit has to be tested in further applications. Nevertheless, the assumption of log-normal distribution is generally in line with empirical evidence that the distribution of environmental goods and 'bads' is non-negative and right-skewed, which makes it a preferred choice over

\footnotetext{
22 Boyle et al. (2009) point out, that structural benefit transfer approaches are only valid, if there is no pre-existing systematic sorting between the study and the policy site regarding unobserved characteristics of preferences for the environmental good. In the equal-preference model studied here this assumption is generally fulfilled, as pre-existing sorting (prior to the valuation study and the policy under consideration) between the study and the policy site only occurs due to differences in income (as preferences are homogeneous). Thus, pre-existing sorting is fully captured by the parameters of the income distributions $\left(\mu_{Y}{ }^{\mathrm{p}}, \mathrm{CV}_{Y}{ }^{\mathrm{p}}, \mu_{Y}{ }^{\mathrm{s}}, \mathrm{CV}_{Y}{ }^{\mathrm{s}}\right)$ and the correlation coefficients $\left(\rho^{\mathrm{p}}, \rho^{\mathrm{s}}\right)$.

23 Measuring exposure to environmental goods and the corresponding environmental inequality is often challenging. While the unit of observation for measuring economic inequality is usually the individual or household, the exposure to environmental goods and 'bads' is usually not known on the level of the individual or household. In order to avoid errors in interfering individual exposure from aggregate data, one should aim at using small-scale data (Boyce et al. 2016). However, in primary valuation studies, it is often straightforward to collect data on the endowment with environmental goods from respondents, for instance, the distance to environmental amenities or the frequency of visits.

24 Recently, there have been remarkable advances in estimating dose-response functions in economics. Schlenker et al. (2015) estimate dose-response functions for air pollution emission from airports in California. Currie et al. (2015) estimate the effect of industrial air pollution on birthweight in five large US states. However, these studies do not investigate how the estimated dose-response function are conditioned by income.
} 
symmetric distributions like a normal distribution. It has been shown, for instance, in the case of Singapore, that access to urban green spaces in cities is strongly right-skewed (Tan and Samsudin 2017), which also holds true for exposure to industrial air pollution in the U.S. (Boyce et al. 2016). Moreover, airborne particulate matter in London seems to follow a log-normal distribution (MacKerron and Morato 2009), as does historic air pollution in English cities (Heblich et al. 2018, Fig. A7ab). While a log-normal distribution thus might be supported with some first empirical evidence, I nevertheless show in Appendix 1.9 that in cases where income and environmental good endowment are distributed independently (Corollary 1), the effect of inequality can be generalized to any mean preserving spread in income or environmental good endowment.

Fourth, I considered household utility in the constant elasticity of substitution (CES) form, which is standard in economic theory. For general ordinal utility functions, the elasticity of substitution is inversely related to the income elasticity of WTP (Ebert 2003; Baumgärtner et al. 2017a), which is, for CES utility, thus also constant. A constant income elasticity of WTP is supported by some empirical evidence (e.g. Jacobsen and Hanley 2009), assumed in many benefit-transfer applications and advised in several governmental guidelines (e.g. OECD 2018). However, there is also empirical evidence that the income elasticity of WTP may vary with mean income (e.g. Barbier et al. 2017). I here studied an equal-preference model, where all differences in WTP arise from differences in endowment with income or the environmental good and not from differences in preferences between rich and poor households. In particular, this model did not capture any effect of the income elasticity of WTP possibly varying with income. An extension of my analysis for a non-constant income elasticity could assume non-homothetic preferences, e.g. due to a minimum subsistence level in consumption (Baumgärtner et al. 2017b; Drupp 2018).

Fifth, I studied a purely statistical effect of environmental and income inequality at the stage of aggregating individual WTPs to obtain a societal value. Beyond this statistical effect also behavioural effects such as inequality aversion or positional externalities might be relevant for how inequality effects societal WTP. For instance, Aronsson and Johansson-Stenman (2008) show that if relative consumption matters then a household's marginal WTP critically depends on whether other households will also have to pay for the public good provision. However, studying relative consumption concerns will in generally require to depart from representing preferences with a CES utility function. The later was a preferred functional form to derive parametrised results that are coherent with current benefit transfer practises.

Finally, I employed the coefficient of variation, $\mathrm{CV}_{E}$, as a measure of environmental inequality, but there are several other measures that one could apply. Using the $\mathrm{CV}_{E}$ is in line with the idea of relative inequality, which feature prominently in scientific and public debates on distributive justice. For instance, Chancel and Piketty (2015) find that relative inequality in individual $\mathrm{CO}_{2}$-eq emissions increased over the period from 1998 to 2013 and interfere from this design options for an equitable financing of global climate adaptation. Nevertheless, one might well argue that when considering the endowment with environmental goods and exposure to environmental pollution, such as air pollution, water pollution or noise, it is the absolute level that matters for health and general well-being and that hence an indicator of absolute inequality — such as the standard deviation or the GINI-coefficient—would be more appropriate. However, employing a relative and thereby unit-less measure was advantageous for the purpose of this study, as it allows a direct comparison between environmental and income inequality (see Propositions 1 and 2). Again, I leave an extension to other measures of environmental inequality for future work. 


\section{Conclusion}

I have studied how environmental and income inequality affect the value of a heterogeneously distributed environmental public good. To this end, I analyzed a model in which households have identical preferences characterized by a constant elasticity of substitution utility function and are heterogeneous in both their endowment with a public good and their income. While the analysis was framed for environmental public goods, it holds more general for all public goods where exposure or access is heterogeneous or depends on location, e.g. public schools, healthcare, transportation infrastructure, historical amenities or coastal defence.

My main results are: (1) the effect of environmental and income inequality on societal WTP for the environmental good is determined by whether the environmental good is a substitute for or a complement to manufactured consumption goods and by how environmental good endowment is correlated with income; (2) an increase in the correlation between environmental good endowment and income-for example, due to richer households sorting into places where environmental quality is high-increases (decreases) societal WTP if and only if the environmental good and consumption goods are substitutes (complements). Moreover, I derived closed-form transfer factors for application in benefit transfer and environmental cost-benefit analysis that account for differences in the distribution of the environmental good and income and which are particularly simple if both are distributed independently. Using forest preservation in Poland as an example, I illustrated that already for small correlations between environmental good endowment and income this theory-based adjustment is associated with considerable effect sizes-increasing societal WTP by up to $8 \%$ for an equal distribution of the environmental good and income compared to the status quo.

These findings extend the recent literature on how income inequality affects societal WTP for homogeneously distributed public goods. In particular, I showed that the key result of Baumgärtner et al. (2017a) according to which societal WTP decreases (increases) with relative income inequality if and only if the environmental good and the consumption good are substitutes (complements) also holds for heterogeneously distributed public goods in cases where (1) they are distributed independently of income, (2) their endowment is negatively correlated with income, or (3) relative income inequality is larger than relative environmental inequality. Moreover, the transfer factor for income inequality proposed by Baumgärtner et al. (2017a) and empirically validated by Meya et al. (2018) for a multicountry valuation study, also holds for heterogeneous distributed public goods uncorrelated with income.

My results are relevant in several respects: First, when applying benefit transfer to value heterogeneously distributed pubic goods one could use the derived formulas to correct for differences in environmental good provision and its correlation with income. Public policy making frequently uses secondary data in cost-benefit analysis, as primary valuation studies are time intensive and costly. Therefore, 'value' or 'benefit transfer' has become a dominant method of environmental valuation (Pearce et al. 2006; Richardson et al. 2015) and is by now "far more pervasive to policy analysis than many perhaps [...] realize" (OECD 2018 , p. 160). The development of benefit transfer methods in the context of heterogeneously distributed public goods is of major importance for environmental policy and management, as most environmental goods are distributed unevenly. Government agencies are required to conduct environmental valuation and cost-benefit analysis on unevenly distributed public goods under several regulatory acts, such as the EU Water Framework 
Directive, the European Marine Strategy Framework Directive, and U.S. regulations like the Clean Air Act. However, even though a grounding of benefit transfers in economic theory is generally held to ensure quality (Smith et al. 2002), the practical application of such structural benefit transfers remains very limited in the domains of policy making and management, probably due to the advanced micro-economic skills required (Phaneuf and Requate 2017, p. 685). Here, I contribute to the development of structural approach to benefit transfer by presenting novel transfer factors to control for differences in the (spatial) distribution of environmental public goods. I thus hope to serve the high policy demand to improve spatially explicit benefit transfer methods for natural capital accounting (United Nations et al. 2014; World Bank 2018), in particular regarding the scaling-up of site-specific WTP estimates to larger areas. ${ }^{25}$ The employed value concept renders my results suitable to policy applications, where the whole stock of an environmental good is valued with a single price, such as in standard national accounting.

Second, my study highlighted the importance of accounting for the spatial distribution of environmental goods and income when aggregating WTP in environmental valuation. It is well known that the aggregation process of individual WTPs itself can substantially shape the resulting societal values (Bateman et al. 2006; Loomis 2000; Smith 1993). Primary valuation studies should report distributional parameters on the valued environment good and income to facilitate more sophisticated environmental cost-benefit analysis. In particular, primary valuation studies eliciting WTP should report how the valued environmental good is distributed, $\mu_{E}$ and $\sigma_{E}$ or $\mathrm{CV}_{E}$, and correlated with income, $\rho$. Moreover, this analysis once more emphasizes that the income elasticity of WTP, $\eta$, which is inversely related to the elasticity of substitution between consumption and environmental goods, is crucial to determine how the distribution of both the environmental good endowment and income affects societal WTP. This points to a need for more robust empirical estimates on $\eta$.

Third, my findings are relevant for environmental policy makers who are concerned with both equity and allocative efficiency. In the context of gentrification, for instance, policy makers might have a preference regarding the correlation of environmental goods with income, $\rho$, and aim at counteracting the distributional effects of decentralized market forces by introducing explicit measures like social housing or spatially sensitive development of urban green spaces. When creating new environmental amenities, place new sources of pollution, or reduce existing ones, the developed transfer factors show how to adjust WTP in line with the new distribution in environmental cost-benefit analysis. Under certain conditions, the developed transfer factors are a specification of distributional weights (Drupp et al. 2018).

Acknowledgements I am grateful to Thomas Aronsson, Stefan Baumgärtner, Simon Dietz, Nils Droste, Moritz Drupp, Udo Ebert, Klaus Eisenack, Nick Hanley, Andreas Lange and Martin Quaas for helpful comments. I would like to thank Mikołaj Czajkowski as well as all researchers contributing to the POLFOREX project (Forest as a public good. Evaluation of social and environmental benefits of forests in Poland to improve management efficiency) for sharing their empirical data, and to its funders, the EEA Financial Mechanism, Norwegian Financial Mechanism, and the Polish Ministry of Science and Higher Education. Moreover, I thank seminar participants at LSE 2019, Oldenburg 2019, Umeå 2018, BIOECON 2018, Berlin DCE Colloquium 2017 and HU Berlin 2017 for stimulating discussions. Finally, financial support from the Ministry for Science and Culture of Lower Saxony (Germany) under Grant VWZN3045 is gratefully acknowledged.

Funding Funding was provided by Niedersächsisches Ministerium für Wissenschaft und Kultur (Grant No. VWZN3045). Open Access funding provided by Projekt DEAL.

25 Another extension that it necessary to make the structural benefit transfer approach of Baumgärtner et al. (2017a) suitable for natural capital accounting is to generalize the model framework from a static to a dynamic setting, as done in Meya et al. (2018). 
Open Access This article is licensed under a Creative Commons Attribution 4.0 International License, which permits use, sharing, adaptation, distribution and reproduction in any medium or format, as long as you give appropriate credit to the original author(s) and the source, provide a link to the Creative Commons licence, and indicate if changes were made. The images or other third party material in this article are included in the article's Creative Commons licence, unless indicated otherwise in a credit line to the material. If material is not included in the article's Creative Commons licence and your intended use is not permitted by statutory regulation or exceeds the permitted use, you will need to obtain permission directly from the copyright holder. To view a copy of this licence, visit http://creativecommons.org/licenses/by/4.0/.

\section{Appendix 1}

\subsection{Derivation of the Household's Total WTP, WTP $\left(Y_{i}, E_{i}\right)$ [Eq. (4)]}

Here I derive the household's marginal and total WTP for the heterogeneously distributed environmental good.

First, consider the constrained maximization problem in Eq. (2). Marginal WTP for the environmental good $E_{i}$ is given by the marginal rate of substitution between the environmental good and income. For CES utility [Eq. (1)] and substituting $X_{i}=\frac{Y_{i}}{P}$ the marginal WTP reads:

$$
w\left(Y_{i}, E_{i}\right):=\frac{\partial U\left(\frac{Y_{i}}{P}, E_{i}\right) / \partial E_{i}}{\partial U\left(\frac{Y_{i}}{P}, E_{i}\right) / \partial Y_{i}} \stackrel{(1)}{=} \frac{1-\alpha}{\alpha} P^{\frac{\theta-1}{\theta}} Y_{i}^{1 / \theta} E_{i}^{-1 / \theta} .
$$

The marginal WTP, $\omega$, can be interpreted as the virtual price the household is willing to pay in a hypothetical choice problem where the household would have voluntarily chosen quantity $E_{i}$, given income $Y_{i}$ and consumption good price $P$.

Second, and equivalently, consider the decision problem in Eq. (3). The corresponding Lagrangian is

$$
L=\left(\alpha X_{i}^{\frac{\theta-1}{\theta}}+(1-\alpha) E_{i}^{\frac{\theta-1}{\theta}}\right)^{\frac{\theta}{\theta-1}}+\lambda\left(\hat{Y}_{i}-P X_{i}-\omega E_{i}\right) .
$$

Taking the partial derivative with respect to $X_{i}$ as well as with respect to $E_{i}$, and setting each to zero gives two first order conditions. Rearranging each for $\lambda$, setting the results equal to each other and rearranging gives $\omega=\frac{1-\alpha}{\alpha} P X_{i}^{1 / \theta} E_{i}^{-1 / \theta}$. Substituting in the remaining first order condition, $X_{i}=\left(\hat{Y}_{i}-\omega E_{i}\right) / P$, using $Y_{i}^{\alpha}=\hat{Y}_{i}^{i}-\omega E_{i}$ to hold income constant and simplifying returns Eq. (25).

Finally, total WTP for the environmental good is defined as marginal WTP, $\omega$, at levels $E_{i}$ and $Y_{i}$ times the level of the environmental good $E_{i}$ (Ebert 2003, p. 442)

$$
\operatorname{WTP}\left(Y_{i}, E_{i}\right):=w\left(Y_{i}, E_{i}\right) E_{i} \stackrel{(\mathrm{A} .25)}{=} \frac{1-\alpha}{\alpha}\left(P E_{i}\right)^{\frac{\theta-1}{\theta}} Y_{i}^{1 / \theta}
$$

where the income elasticity of WTP, $\eta$, is the inverse of the elasticity of substitution, $\eta=\frac{1}{\theta}$. Hence, WTP can also be written directly for the income elasticity of WTP as

$$
\mathrm{WTP}\left(Y_{i}, E_{i}\right)=\frac{1-\alpha}{\alpha}\left(P E_{i}\right)^{1-\eta} Y_{i}^{\eta}
$$




\subsection{Derivation of Mean WTP, $\mu_{\text {WTP, [Eq. (10)] }}$}

Mean WTP, $\mu_{\mathrm{WTP}}$ [Eq. (7)], can be reformulated with respect to the moments of the bivariate log-normal distribution - $\mu_{Y}, \sigma_{Y}, \mu_{E}, \sigma_{E}, \rho$ - as follows

$$
\begin{aligned}
& \mu_{\mathrm{WTP}}\left(\mu_{Y}, \sigma_{Y}, \mu_{E}, \sigma_{E}, \rho\right)=\int_{0}^{\infty} \int_{0}^{\infty} f_{\ln }\left(Y, E ; \mu_{Y}, \sigma_{Y}, \mu_{E}, \sigma_{E}, \rho\right) \operatorname{WTP}(Y, E) d Y d E \\
& \stackrel{\text { (A.27) }}{=} \int_{0}^{\infty} \int_{0}^{\infty} f_{\ln }\left(Y, E ; \mu_{Y}, \sigma_{Y}, \mu_{E}, \sigma_{E}, \rho\right) \frac{1-\alpha}{\alpha} P^{1-\eta} E^{1-\eta} Y^{\eta} d Y d E \\
& =\frac{1-\alpha}{\alpha} P^{1-\eta} \int_{0}^{\infty} \int_{0}^{\infty} f_{\ln }\left(Y, E ; \mu_{Y}, \sigma_{Y}, \mu_{E}, \sigma_{E}, \rho\right) E^{1-\eta} Y^{\eta} d Y d E \\
& \stackrel{(8)}{=} \frac{1-\alpha}{\alpha} P^{1-\eta} \int_{0}^{\infty} \int_{0}^{\infty} \frac{\exp \left[-\frac{1}{2\left(1-\rho^{2}\right)}\left(\frac{\left(\ln (Y)-m_{Y}\right)^{2}}{s_{Y}^{2}}-2 \rho \frac{\ln (Y)-m_{Y}}{s_{Y}} \frac{\ln (E)-m_{E}}{s_{E}}+\frac{\left(\ln (E)-m_{E}\right)^{2}}{s_{E}^{2}}\right)\right]}{2 \pi Y E \sqrt{s_{Y}^{2} s_{E}^{2}\left(1-\rho^{2}\right)}} E^{1-\eta} Y^{\eta} d Y d E \\
& =\frac{1-\alpha}{\alpha} P^{1-\eta} \int_{0}^{\infty} \int_{0}^{\infty} \frac{\exp \left[-\frac{1}{2\left(1-\rho^{2}\right)}\left(\frac{\left(\ln (Y)-m_{Y}\right)^{2}}{s_{Y}^{2}}-2 \rho \frac{\ln (Y)-m_{Y}}{s_{Y}} \frac{\ln (E)-m_{E}}{s_{E}}+\frac{\left(\ln (E)-m_{E}\right)^{2}}{s_{E}^{2}}\right)\right]}{2 \pi \sqrt{s_{Y}^{2} s_{E}^{2}\left(1-\rho^{2}\right)}} E^{-\eta} Y^{\eta-1} d Y d E \\
& =\frac{1-\alpha}{\alpha} P^{1-\eta} \int_{0}^{\infty} \frac{1}{\sqrt{2 \pi s_{Y}^{2}}} \exp \left[-\frac{m_{E}+\eta^{2}\left(\rho^{2}-1\right) s_{E}^{2} s_{Y}^{2}+2 \eta s_{E}\left(-s_{E} m_{Y}+\rho m_{E} s_{Y}\right)+\ln (E)^{2}}{2 s_{E}}\right] \\
& E^{\frac{m_{E}+\eta s_{E}\left(-s_{E}+\rho s_{Y}\right)}{s_{E}^{2}}} d E \\
& =\frac{1-\alpha}{\alpha} P^{1-\eta} \exp \left[\frac{1}{2}(\eta-1)^{2} s_{E}^{2}+\eta\left(m_{Y}-m_{E}\right)+m_{E}-\rho(\eta-1) \eta s_{E} s_{Y}+\frac{1}{2} \eta^{2} s_{Y}^{2}\right] \\
& \stackrel{(9)}{=} \frac{1-\alpha}{\alpha} P^{1-\eta} \exp \left[\frac{1}{2}(\eta-1)^{2} \ln \left(1+\frac{\sigma_{E}^{2}}{\mu_{E}^{2}}\right)+\eta\left(\ln \left(\mu_{Y}\right)-\frac{1}{2} \ln \left(1+\frac{\sigma_{Y}^{2}}{\mu_{Y}^{2}}\right)-\ln \left(\mu_{E}\right)+\frac{1}{2} \ln \left(1+\frac{\sigma_{E}^{2}}{\mu_{E}^{2}}\right)\right)\right. \\
& \left.+\ln \left(\mu_{E}\right)-\frac{1}{2} \ln \left(1+\frac{\sigma_{E}^{2}}{\mu_{E}^{2}}\right)-\rho(\eta-1) \eta \sqrt{\ln \left(1+\frac{\sigma_{E}^{2}}{\mu_{E}^{2}}\right)} \sqrt{\ln \left(1+\frac{\sigma_{Y}^{2}}{\mu_{Y}^{2}}\right)}+\frac{1}{2} \eta^{2} \ln \left(1+\frac{\sigma_{Y}^{2}}{\mu_{Y}^{2}}\right)\right] \\
& =\frac{1-\alpha}{\alpha} P^{1-\eta} \exp \left[\frac{\eta^{2}-\eta}{2} \ln \left(1+\frac{\sigma_{E}^{2}}{\mu_{E}^{2}}\right)+\frac{\eta^{2}-\eta}{2} \ln \left(1+\frac{\sigma_{Y}^{2}}{\mu_{Y}^{2}}\right)+(1-\eta) \ln \left(\mu_{E}\right)+\eta \ln \left(\mu_{Y}\right)\right. \\
& \left.-\rho(\eta-1) \eta \sqrt{\ln \left(1+\frac{\sigma_{E}^{2}}{\mu_{E}^{2}}\right)} \sqrt{\ln \left(1+\frac{\sigma_{Y}^{2}}{\mu_{Y}^{2}}\right)}\right] \\
& =\frac{1-\alpha}{\alpha} P^{1-\eta} \exp \left[\ln \left[\left(1+\frac{\sigma_{E}^{2}}{\mu_{E}^{2}}\right)^{\frac{\eta^{2}-\eta}{2}}\right)\right] \exp \left[\ln \left[\left(1+\frac{\sigma_{Y}^{2}}{\mu_{Y}^{2}}\right)^{\frac{\eta^{2}-\eta}{2}}\right)\right] \exp \left[\ln \left(\mu_{E}^{1-\eta}\right)\right] \exp \left[\ln \left(\mu_{Y}^{\eta}\right)\right] \\
& \exp \left[-\rho(\eta-1) \eta \sqrt{\ln \left(1+\frac{\sigma_{E}^{2}}{\mu_{E}^{2}}\right)} \sqrt{\ln \left(1+\frac{\sigma_{Y}^{2}}{\mu_{Y}^{2}}\right)}\right] \\
& =\frac{1-\alpha}{\alpha} P^{1-\eta} \mu_{Y}^{\eta}\left(1+\frac{\sigma_{Y}^{2}}{\mu_{Y}^{2}}\right)^{\frac{\eta^{2}-\eta}{2}} \mu_{E}^{1-\eta}\left(1+\frac{\sigma_{E}^{2}}{\mu_{E}^{2}}\right)^{\frac{\eta^{2}-\eta}{2}} \exp \left[\rho\left(-\eta^{2}+\eta\right) \sqrt{\ln \left(1+\frac{\sigma_{E}^{2}}{\mu_{E}^{2}}\right) \ln \left(1+\frac{\sigma_{Y}^{2}}{\mu_{Y}^{2}}\right)}\right]
\end{aligned}
$$




$$
\stackrel{\eta=1 / \theta}{=} \frac{1-\alpha}{\alpha} P^{\frac{\theta-1}{\theta}} \mu_{Y}^{\frac{1}{\theta}}\left(1+\frac{\sigma_{Y}^{2}}{\mu_{Y}^{2}}\right)^{\frac{1-\theta}{2 \theta^{2}}} \mu_{E}^{\frac{\theta-1}{\theta}}\left(1+\frac{\sigma_{E}^{2}}{\mu_{E}^{2}}\right)^{\frac{1-\theta}{2 \theta^{2}}} \exp \left[\rho \frac{\theta-1}{\theta^{2}} \sqrt{\ln \left(1+\frac{\sigma_{E}^{2}}{\mu_{E}^{2}}\right) \ln \left(1+\frac{\sigma_{Y}^{2}}{\mu_{Y}^{2}}\right)}\right] \text {. }
$$

Equivalently mean WTP can be expressed for relative income inequality, $\mathrm{CV}_{Y}:=\frac{\sigma_{Y}}{\mu_{Y}}$, and relative environmental inequality, $\mathrm{CV}_{E}:=\frac{\sigma_{E}}{\mu_{E}}$. Equation (29) then becomes:

$$
\begin{aligned}
\mu_{\mathrm{WTP}}\left(\mu_{Y}, \mathrm{CV}_{Y}, \mu_{E}, \mathrm{CV}_{E}, \rho\right) & =\frac{1-\alpha}{\alpha} P^{\frac{\theta-1}{\theta}} \mu_{Y}^{\frac{1}{\theta}}\left(1+\mathrm{CV}_{Y}^{2}\right)^{\frac{1-\theta}{2 \theta^{2}}} \mu_{E}^{\frac{\theta-1}{\theta}}\left(1+\mathrm{CV}_{E}^{2}\right)^{\frac{1-\theta}{2 \theta^{2}}} \Psi, \\
\text { with } \quad \Psi\left(\mathrm{CV}_{Y}, \mathrm{CV}_{E}, \rho\right) & :=\exp \left[\rho \frac{\theta-1}{\theta^{2}} \sqrt{\ln \left(1+\mathrm{CV}_{E}^{2}\right) \ln \left(1+\mathrm{CV}_{Y}^{2}\right)}\right] .
\end{aligned}
$$

\subsection{Proof of Proposition 1}

Differentiating $\mu_{\mathrm{WTP}}$ given in Eq. (10) with respect to $\mathrm{CV}_{Y}$ yields

$$
\begin{aligned}
\frac{\partial \mu_{\mathrm{WTP}}\left(\mu_{Y}, \mathrm{CV}_{Y}, \mu_{E}, \mathrm{CV}_{E}, \rho\right)}{\partial \mathrm{CV}_{Y}} & =k^{\prime} \frac{1-\theta}{\theta^{2}} \mathrm{CV}_{Y}\left(1+\mathrm{CV}_{Y}^{2}\right)^{\frac{1-\theta-2 \theta^{2}}{2 \theta^{2}}} \Psi+k^{\prime}\left(1+\mathrm{CV}_{Y}^{2}\right)^{\frac{1-\theta}{2 \theta^{2}}} \Psi \rho \frac{\theta-1}{\theta^{2}} \\
& \frac{\ln \left(1+\mathrm{CV}_{E}^{2}\right)}{\sqrt{\ln \left(1+\mathrm{CV}_{E}^{2}\right) \ln \left(1+\mathrm{CV}_{Y}^{2}\right)}} \frac{\mathrm{CV}_{Y}}{1+\mathrm{CV}_{Y}^{2}} \\
= & k^{\prime} \Psi \mathrm{CV}_{Y}\left(1+\mathrm{CV}_{Y}^{2}\right)^{\frac{1-\theta-2 \theta^{2}}{2 \theta^{2}}}\left[\frac{1-\theta}{\theta^{2}}+\rho \frac{\theta-1}{\theta^{2}} \frac{\ln \left(1+\mathrm{CV}_{E}^{2}\right)}{\sqrt{\ln \left(1+\mathrm{CV}_{E}^{2}\right) \ln \left(1+\mathrm{CV}_{Y}^{2}\right)}}\right] \\
= & k^{\prime} \Psi \frac{1-\theta}{\theta^{2}} \mathrm{CV}_{Y}\left(1+\mathrm{CV}_{Y}^{2}\right)^{\frac{1-\theta-2 \theta^{2}}{2 \theta^{2}}}\left[1-\rho \sqrt{\left.\frac{\ln \left(1+\mathrm{CV}_{E}^{2}\right)}{\ln \left(1+\mathrm{CV}_{Y}^{2}\right)}\right],}\right.
\end{aligned}
$$

where

$$
\begin{gathered}
\Psi\left(\mathrm{CV}_{Y}, \mathrm{CV}_{E}, \rho\right):=\exp \left[\rho \frac{\theta-1}{\theta^{2}} \sqrt{\ln \left(1+\mathrm{CV}_{E}^{2}\right) \ln \left(1+\mathrm{CV}_{Y}^{2}\right)}\right], \\
k^{\prime}\left(\mu_{Y}, \mu_{E}, \mathrm{CV}_{E}\right):=\frac{1-\alpha}{\alpha} P^{\frac{\theta-1}{\theta}} \mu_{Y}^{\frac{1}{\theta}}\left(1+\mathrm{CV}_{E}^{2}\right)^{\frac{1-\theta}{2 \theta^{2}}} \mu_{E}^{\frac{\theta-1}{\theta}} .
\end{gathered}
$$

As $\mathrm{CV}_{E}, k^{\prime}$ and $\Psi$ are strictly positive, Eq. (31) can only become negative if either $\frac{1-\theta}{\theta^{2}}<0$, or $1-\rho \sqrt{\frac{\ln \left(1+\mathrm{CV}_{E}^{2}\right)}{\ln \left(1+\mathrm{CV}_{Y}^{2}\right)}}<0$, while the respective other factor is strictly positive. It holds that

$$
\frac{1-\theta}{\theta^{2}} \gtreqless 0 \Longleftrightarrow \theta \lesseqgtr 1
$$

and 


$$
1-\rho \sqrt{\frac{\ln \left(1+\mathrm{CV}_{E}{ }^{2}\right)}{\ln \left(1+\mathrm{CV}_{Y}{ }^{2}\right)}} \gtreqless 0 \Longleftrightarrow \rho \lesseqgtr \sqrt{\frac{\ln \left(1+\mathrm{CV}_{Y}{ }^{2}\right)}{\ln \left(1+\mathrm{CV}_{E}^{2}\right)}} .
$$

The combination of the sign of both factors establishes the Proposition.

\subsection{Proof of Proposition 2}

The proof is completely analogous to the one for Proposition 1 . Differentiating $\mu_{\mathrm{WTP}}$ given in Eq. (10) with respect to $\mathrm{CV}_{E}$ yields

$$
\begin{aligned}
& \frac{\partial \mu_{\mathrm{WTP}}\left(\mu_{Y}, \mathrm{CV}_{Y}, \mu_{E}, \mathrm{CV}_{E}, \rho\right)}{\partial \mathrm{CV}_{E}} \\
& =k^{\prime \prime} \frac{1-\theta}{\theta^{2}} \mathrm{CV}_{E}\left(1+\mathrm{CV}_{E}^{2}\right)^{\frac{1-\theta-2 \theta^{2}}{2 \theta^{2}}} \Psi\left[1-\rho \sqrt{\frac{\ln \left(1+\mathrm{CV}_{Y}^{2}\right)}{\ln \left(1+\mathrm{CV}_{E}^{2}\right)}}\right],
\end{aligned}
$$

where

$$
\begin{gathered}
\Psi\left(\mathrm{CV}_{Y}, \mathrm{CV}_{E}, \rho\right):=\exp \left[\rho \frac{\theta-1}{\theta^{2}} \sqrt{\ln \left(1+\mathrm{CV}_{E}^{2}\right) \ln \left(1+\mathrm{CV}_{Y}^{2}\right)}\right], \\
k^{\prime \prime}\left(\mu_{Y}, \mathrm{CV}_{Y}, \mu_{E}\right):=\frac{1-\alpha}{\alpha} P^{\frac{\theta-1}{\theta}} \mu_{Y}^{\frac{1}{\theta}}\left(1+\mathrm{CV}_{Y}^{2}\right)^{\frac{1-\theta}{2 \theta^{2}}} \mu_{E}^{\frac{\theta-1}{\theta}} .
\end{gathered}
$$

As $\mathrm{CV}_{E}, k$ and $\Psi$ are strictly positive, the sign of Eq. (36) is determined by the sign of the factors $\frac{1-\theta}{\theta^{2}}<0$ and $1+\rho \sqrt{\frac{\ln \left(1+\mathrm{CV}_{Y}^{2}\right)}{\ln \left(1+\mathrm{CV}_{E}^{2}\right)}}<0$. It holds that

$$
\frac{1-\theta}{\theta^{2}} \gtreqless 0 \Longleftrightarrow \theta \lesseqgtr 1
$$

and

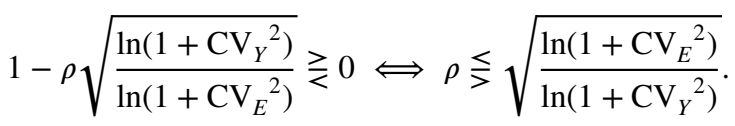

The combination of the sign of both factors establishes the Proposition.

\subsection{Proof of Corollary 1}

Differentiating $\mu_{\mathrm{WTP}}^{\mathrm{ind}}$ given in Eq. (11) with respect to income inequality, $\mathrm{CV}_{Y}$, yields

$$
\begin{aligned}
& \frac{\partial \mu_{\mathrm{WTP}}^{\mathrm{ind}}\left(\mu_{Y}, \mathrm{CV}_{Y}, \mu_{E}, \mathrm{CV}_{E}\right)}{\partial \mathrm{CV}_{Y}} \\
& \quad=\frac{1-\theta}{\theta^{2}} \frac{1-\alpha}{\alpha} P^{\frac{\theta-1}{\theta}} \mu_{Y}^{1 / \theta} \mathrm{CV}_{Y}\left(1+\mathrm{CV}_{Y}^{2}\right)^{\frac{1-\theta-2 \theta^{2}}{2 \theta^{2}}} \mu_{E}^{\frac{\theta-1}{\theta}}\left(1+\mathrm{CV}_{E}^{2}\right)^{\frac{1-\theta}{2 \theta^{2}}}
\end{aligned}
$$

Differentiating $\mu_{\mathrm{WTP}}^{\text {ind }}$, Eq. (11), with respect to environmental inequality, $\mathrm{CV}_{E}$, yields 


$$
\begin{aligned}
& \frac{\partial \mu_{\mathrm{WTP}}^{\mathrm{ind}}\left(\mu_{Y}, \mathrm{CV}_{Y}, \mu_{E}, \mathrm{CV}_{E}\right)}{\partial \mathrm{CV}_{E}} \\
& \quad=\frac{1-\theta}{\theta^{2}} \frac{1-\alpha}{\alpha} P^{\frac{\theta-1}{\theta}} \mu_{Y}^{1 / \theta}\left(1+\mathrm{CV}_{Y}^{2}\right)^{\frac{1-\theta}{2 \theta^{2}}} \mu_{E}^{\frac{\theta-1}{\theta}} \mathrm{CV}_{E}\left(1+\mathrm{CV}_{E}^{2}\right)^{\frac{1-\theta-2 \theta^{2}}{2 \theta^{2}}}
\end{aligned}
$$

As $\alpha \in(0,1)$ and $\theta, P, \mu_{Y}, \mathrm{CV}_{Y}, \mu_{E}, \mathrm{CV}_{E}>0$ the sign of both derivatives is determined by the sign of $\frac{1-\theta}{\theta^{2}}$. It holds that $\frac{1-\theta}{\theta^{2}} \lesseqgtr 0 \Longleftrightarrow \theta \gtreqless 1$.

\subsection{Household Sorting with Respect to the Distribution of the Environmental Good}

Household sorting generally affects the correlation between income and endowment with environmental goods. I outline how this can be formally proven for CES preferences and common assumptions on the housing market in the following. To this end, I present a stylized model of how the distribution of environmental goods affects the residential choice ('sorting') of households that differ in income. The endowment with the environmental good is now a choice variable in the household's decision problem.

Consider a city, region, or country with an environmental amenity, the exposure to which is distributed unevenly and continuously over locations. Following Tiebout (1956) each household $i$ is perfectly mobile and chooses its location with the aim of enjoying a desired level of the environmental good, $E_{i}>0$. For instance, the environmental good endowment $E_{i}$ could be measured as the inverse of the Euclidean distance to the environmental amenity. It is therefore illustrative to consider $E_{i} \in(0,1)$.

As before, households have identical preferences over a consumption good, $X_{i}$, and the environmental good, $E_{i}$, represented by a CES utility function [see Eq. (1)]. Thus, like Lee and Lin (2018) and Heblich et al. (2018), I abstract from other property characteristics (such as size) and implicitly assume non-environmental property characteristics to be identical across locations.

Household $i$ 's decision problem is then to maximize utility by choosing any combination of these goods subject to a budget constraint,

$$
\max _{X_{i}, E_{i}} U\left(X_{i}, E_{i}\right) \quad \text { s.t. } P X_{i}+R\left(E_{i}\right)=Y_{i},
$$

where $Y_{i}$ is household income and $R\left(E_{i}\right)$ is the annual rent collected by absentee landlords. Studying rents rather than property prices makes it possible to consider a static setting and abstract from dynamic effects. To save on notation, I assume $P=1$, i.e. $X_{i}$ is the numeraire good. Rearranging the budget constraint and substituting for $X_{i}$, household's utility can be rewritten as $U\left(Y_{i}-R\left(E_{i}\right), E_{i}\right)$.

In equilibrium, the rent $R\left(E_{i}\right)$ has to vary over $E_{i}$ so that utility is uniform across locations (e.g., Brueckner et al. 1999; Phaneuf and Requate 2017, 532). Let $\bar{u}$ denote the reference utility level so that

$$
\bar{u}=U\left(Y_{i}-\bar{R}\left(E_{i}\right), E_{i}\right),
$$

where $\bar{R}\left(E_{i}\right)$ is by definition the maximum household $i$ is willing to pay for a home in a location characterized by an environmental good at level $\left(E_{i}\right)$ and hence referred to as household's bid function.

The slope of the bid function or the marginal WTP for an increase in the environmental good is then given as derivative of the implicit bid function $\bar{R}\left(E_{i}\right)$ with respect to the environmental good: 


$$
\frac{\partial \bar{R}\left(E_{i}\right)}{\partial E_{i}}=\frac{\frac{\partial U}{\partial E_{i}}\left(Y_{j}-\bar{R}_{j}(\hat{E}), E_{i}\right)}{\frac{\partial U}{\partial X_{i}}\left(Y_{j}-\bar{R}_{j}(\hat{E}), E_{i}\right)} .
$$

Substituting the partial derivatives

$$
\begin{gathered}
\frac{\partial U\left(X_{i}, E_{i}\right)}{\partial E_{i}}=(1-\alpha) E^{-1 / \theta}\left[\alpha X_{i}^{\frac{\theta-1}{\theta}}+(1-\alpha) E_{i}^{\frac{\theta-1}{\theta}}\right]^{\frac{1}{\theta-1}} \text { and } \\
\frac{\partial U\left(X_{i}, E_{i}\right)}{\partial X_{i}}=\alpha X^{-1 / \theta}\left[\alpha X_{i}^{\frac{\theta-1}{\theta}}+(1-\alpha) E_{i}^{\frac{\theta-1}{\theta}}\right]^{\frac{1}{\theta-1}}
\end{gathered}
$$

into Eq. (45) I obtain the slope of the bid function with respect to a change in $E_{i}$

$$
\frac{\partial \bar{R}\left(E_{i}\right)}{\partial E_{i}}=\frac{1-\alpha}{\alpha}\left(\frac{Y_{i}-\bar{R}\left(E_{i}\right)}{E_{i}}\right)^{1 / \theta},
$$

which is strictly increasing in income as by definition $Y_{i}>R\left(E_{i}\right)$ and $\alpha \in(0,1), E_{i}>0$. Note that Eq. (48) almost resembles the marginal WTP derived for an exogenously given $E_{i}$ [see Eq. (25)], except that the household has to pay rent $\bar{R}\left(E_{i}\right)$ to enjoy the environmental good at level $E_{i}$.

Now, I extend this model to a situation with two groups of households $j, k$, that only differ in income $Y_{j} \neq Y_{k}$. Without a loss of generality, I assume $Y_{j}>Y_{k}$. For the remainder, I proceed analogously to the argument presented by Brueckner et al. (1999). Landlords rent houses to the households that pay the highest rent. Thus, the income group that outbids the other income group on the housing market will live where the endowment with $E$ is high. Let $\hat{E}$ denote the threshold level of $E$ where the group's bids are equal $\bar{R}_{j}(\hat{E})=\bar{R}_{k}(\hat{E})$. The relative slopes of the bid-price curves at the threshold $\hat{E}$ determine whether the poor or the rich live in the part of the city (or region or country) where the endowment with the environmental good is high (cf. Brueckner et al. 1999, pp. 96-97): If $\frac{\partial R_{j}}{\partial E}(\hat{E})$ is greater (smaller) $\frac{\partial \bar{R}_{k}}{\partial E}(\hat{E})$ than the rich (poor) will live where environmental quality is higher. The differences between the slopes of the bidfunctions is given as:

$$
\begin{gathered}
\Delta:=\frac{\partial \bar{R}_{j}}{\partial E}(\hat{E})-\frac{\partial \bar{R}_{k}}{\partial E}(\hat{E}) \\
\stackrel{E q .(\mathrm{A} .48)}{=} \frac{1-\alpha}{\alpha}\left[\left(\frac{Y_{j}-\bar{R}_{j}(\hat{E})}{\hat{E}}\right)^{1 / \theta}-\left(\frac{Y_{k}-\bar{R}_{k}(\hat{E})}{\hat{E}}\right)^{1 / \theta}\right],
\end{gathered}
$$

which is strictly greater than zero, as by definition $Y_{j}>Y_{k}$ and $\bar{R}_{j}(\hat{E})=\bar{R}_{k}(\hat{E})$.

Thus, if the marginal WTP matters for sorting on the housing market and as the marginal WTP increases with income, rich (poor) households will sort into locations with high (low) environmental quality. As a result, sorting will increase the correlation between income and endowment with the environmental good $\rho$. 


\subsection{Proof of Proposition 3}

Differentiating $\mu_{\mathrm{WTP}}$ given in Eq. (10) with respect to $\rho$ yields

$$
\begin{aligned}
& \frac{\partial \mu_{\mathrm{WTP}}\left(\mu_{Y}, \mathrm{CV}_{Y}, \mu_{E}, \mathrm{CV}_{E}, \rho\right)}{\partial \rho} \\
& =\frac{\theta-1}{\theta^{2}} \frac{1-\alpha}{\alpha} P^{\frac{\theta-1}{\theta}} \mu_{Y}^{\frac{1}{\theta}}\left(1+\mathrm{CV}_{Y}^{2}\right)^{\frac{1-\theta}{2 \theta^{2}}} \mu_{E}^{\frac{\theta-1}{\theta}}\left(1+\mathrm{CV}_{E}^{2}\right)^{\frac{1-\theta}{2 \theta^{2}}} \sqrt{\ln \left(1+\mathrm{CV}_{E}^{2}\right) \ln \left(1+\mathrm{CV}_{Y}^{2}\right)} \Psi, \\
& \quad \text { where } \quad \Psi\left(\mathrm{CV}_{Y}, \mathrm{CV}_{E}, \rho\right):=\exp \left[\rho \frac{\theta-1}{\theta^{2}} \sqrt{\ln \left(1+\mathrm{CV}_{E}^{2}\right) \ln \left(1+\mathrm{CV}_{Y}^{2}\right)}\right],
\end{aligned}
$$

the sign of which is determined by $\frac{\theta-1}{\theta^{2}}$, as $\alpha \in(0,1)$ and $P, \mu_{E}, \mu_{Y}, \mathrm{CV}_{Y}, \mathrm{CV}_{E}>0$. It holds that $\frac{\theta-1}{\theta^{2}} \gtreqless 0 \Longleftrightarrow \theta \gtreqless 1$.

\subsection{Proof of Proposition 4}

The transfer function, defined as the quotient of mean WTPs at the policy site, $\mathrm{p}$, and at the study site, $\mathrm{s}$, is given as:

$$
\begin{aligned}
\mathcal{T}\left(P^{\mathrm{p}}, \mu_{Y}^{\mathrm{p}}, \mathrm{CV}_{Y}^{\mathrm{p}}, \mu_{E}^{\mathrm{p}}, \mathrm{CV}_{E}^{\mathrm{p}}, \rho^{\mathrm{p}} ; P^{\mathrm{s}}, \mu_{Y}^{\mathrm{s}}, \mathrm{CV}_{Y}^{\mathrm{s}}, \mu_{E}^{\mathrm{s}}, \mathrm{CV}_{E}^{\mathrm{s}}, \rho^{\mathrm{s}}\right) \\
:=\frac{\mu_{\mathrm{WTP}}^{\mathrm{p}}\left(\mu_{Y}, \mathrm{CV}_{Y}, \mu_{E}, \mathrm{CV}_{E}, \rho\right)}{\mu_{\mathrm{WTP}}^{\mathrm{s}}\left(\mu_{Y}, \mathrm{CV}_{Y}, \mu_{E}, \mathrm{CV}_{E}, \rho\right)} \\
\stackrel{\left(P^{\mathrm{p}}\right)^{\frac{\theta-1}{\theta}}\left(\mu_{Y}^{\mathrm{p}}\right)^{\frac{1}{\theta}}\left(1+\mathrm{CV}_{Y}^{\mathrm{p} 2}\right)^{\frac{1-\theta}{\theta^{2}}}\left(\mu_{E}^{\mathrm{p}}\right)^{\frac{\theta-1}{\theta}}\left(1+\mathrm{CV}_{E}^{\mathrm{p} 2}\right)^{\frac{1-\theta}{\theta^{2}}} \exp \left[\rho^{\mathrm{p}} \frac{\theta-1}{\theta^{2}} \sqrt{\ln \left(1+\mathrm{CV}_{Y}^{\mathrm{p} 2}\right) \ln \left(1+\mathrm{CV}_{E}^{\mathrm{p} 2}\right)}\right]}{\left(P^{\mathrm{s}}\right)^{\frac{\theta-1}{\theta}}\left(\mu_{Y}^{\mathrm{s}}\right)^{\frac{1}{\theta}}\left(1+\mathrm{CV}_{Y}^{\mathrm{s} 2}\right)^{\frac{1-\theta}{2 \theta^{2}}}\left(\mu_{E}^{\mathrm{s}}\right)^{\frac{\theta-1}{\theta}}\left(1+\mathrm{CV}_{E}^{\mathrm{s} 2}\right)^{\frac{1-\theta}{2 \theta^{2}}} \exp \left[\rho^{\mathrm{s} \frac{\theta-1}{\theta^{2}}} \sqrt{\ln \left(1+\mathrm{CV}_{Y}^{\mathrm{s} 2}\right) \ln \left(1+\mathrm{CV}_{E}^{\mathrm{s} 2}\right)}\right]} \\
=\left(\frac{P^{\mathrm{p}}}{P^{\mathrm{s}}}\right)^{\frac{\theta-1}{\theta}} \cdot\left(\frac{\mu_{Y}^{\mathrm{p}}}{\mu_{Y}^{\mathrm{s}}}\right)^{\frac{1}{\theta}} \cdot\left(\frac{\mu_{E}^{\mathrm{p}}}{\mu_{E}^{\mathrm{s}}}\right)^{\frac{\theta-1}{\theta}} \cdot\left(\frac{1+\mathrm{CV}_{Y}^{\mathrm{p} 2}}{1+\mathrm{CV}_{Y}^{\mathrm{s} 2}}\right)^{\frac{1-\theta}{2 \theta^{2}}} \cdot\left(\frac{1+\mathrm{CV}_{E}^{\mathrm{p} 2}}{1+\mathrm{CV}_{E}^{\mathrm{s} 2}}\right)^{\frac{1-\theta}{2 \theta^{2}}} \\
\quad \cdot \exp \left[\frac{\theta-1}{\theta^{2}}\left(\rho^{\mathrm{p}} \sqrt{\ln \left(1+\mathrm{CV}_{Y}^{\mathrm{p} 2}\right) \ln \left(1+\mathrm{CV}_{E}^{\mathrm{p} 2}\right)}-\rho^{\mathrm{s}} \sqrt{\ln \left(1+\mathrm{CV}_{Y}^{\mathrm{s}} 2\right) \ln \left(1+\mathrm{CV}_{E}^{\mathrm{s} 2}\right)}\right)\right] .
\end{aligned}
$$

If the environmental good and income are distributed independently at both study and policy site, $\rho^{\mathrm{p}}=\rho^{\mathrm{s}}=0$, the transfer function simplifies to:

$$
\begin{aligned}
& \mathcal{T}^{\text {ind }}\left(P^{\mathrm{p}}, \mu_{Y}^{\mathrm{p}}, \mathrm{CV}_{Y}^{\mathrm{p}}, \mu_{E}^{\mathrm{p}}, \mathrm{CV}_{E}^{\mathrm{p}} ; P^{\mathrm{s}}, \mu_{Y}^{\mathrm{s}}, \mathrm{CV}_{Y}^{\mathrm{s}}, \mu_{E}^{\mathrm{s}}, \mathrm{CV}_{E}^{\mathrm{s}}\right) \\
& :=\frac{\mu_{\mathrm{WTP}}^{\text {ind, }}\left(\mu_{Y}, \mathrm{CV}_{Y}, \mu_{E}, \mathrm{CV}_{E}\right)}{\mu_{\mathrm{WTP}}^{\text {ind, }}\left(\mu_{Y}, \mathrm{CV}_{Y}, \mu_{E}, \mathrm{CV}_{E}\right)} \\
& \stackrel{E q .(11))}{=} \frac{\frac{1-\alpha}{\alpha}\left(P^{\mathrm{p}}\right)^{\frac{\theta-1}{\theta}}\left(\mu_{Y}^{\mathrm{p}}\right)^{\frac{1}{\theta}}\left(1+\mathrm{CV}_{Y}^{\mathrm{p} 2}\right)^{\frac{1-\theta}{2 \theta^{2}}}\left(\mu_{E}^{\mathrm{p}}\right)^{\frac{\theta-1}{\theta}}\left(1+\mathrm{CV}_{E}^{\mathrm{p} 2}\right)^{\frac{1-\theta}{2 \theta^{2}}}}{\frac{1-\alpha}{\alpha}\left(P^{\mathrm{s}}\right)^{\frac{\theta-1}{\theta}}\left(\mu_{Y}^{\mathrm{s}}\right)^{\frac{1}{\theta}}\left(1+\mathrm{CV}_{Y}^{\mathrm{s} 2}\right)^{\frac{1-\theta}{2 \theta^{2}}}\left(\mu_{E}^{\mathrm{s}}\right)^{\frac{\theta-1}{\theta}}\left(1+\mathrm{CV}_{E}^{\mathrm{s} 2}\right)^{\frac{1-\theta}{2 \theta^{2}}}} \\
& =\left(\frac{P^{\mathrm{p}}}{P^{\mathrm{s}}}\right)^{\frac{\theta-1}{\theta}} \cdot\left(\frac{\mu_{Y}^{\mathrm{p}}}{\mu_{Y}^{\mathrm{s}}}\right)^{\frac{1}{\theta}} \cdot\left(\frac{1+\mathrm{CV}_{Y}^{\mathrm{p} 2}}{1+\mathrm{CV}_{Y}^{\mathrm{s} 2}}\right)^{\frac{1-\theta}{2 \theta^{2}}} \cdot\left(\frac{\mu_{E}^{\mathrm{p}}}{\mu_{E}^{\mathrm{s}}}\right)^{\frac{\theta-1}{\theta}} \cdot\left(\frac{1+\mathrm{CV}_{E}^{\mathrm{p} 2}}{1+\mathrm{CV}_{E}^{\mathrm{s} 2}}\right)^{\frac{1-\theta}{2 \theta^{2}}},
\end{aligned}
$$

which can also be obtained by assuming $\rho^{\mathrm{p}}=\rho^{\mathrm{s}}=0$ in Eq. (51). 


\subsection{Generalisation of Corollary 1}

Assume that $Y$ and $E$ are both independently and randomly distributed. (Note, that this includes the special case where $E$ is homogeneously distributed and only $Y$ is randomly distributed or vice versa.) Then the following holds: Mean WTP increases (decreases) for any mean preserving spread in $Y$ or for any mean preserving spread in $E$ if and only if the environmental good is a complement (substitute) to the manufactured consumption good.

Proof Writing mean WTP as expectation for independently, randomly distributed income and environmental good endowment

$$
\begin{gathered}
\mu_{\mathrm{WTP}}=\mathbb{E}\left[\frac{1-\alpha}{\alpha} P^{\frac{\theta-1}{\theta}} l(E) k(Y)\right] \\
=\frac{1-\alpha}{\alpha} P^{\frac{\theta-1}{\theta}} \mathbb{E}[l(E) k(Y)],
\end{gathered}
$$

where $k\left(Y_{\theta-1}:=Y_{i}^{1 / \theta}\right.$ is a convex (concave) function of $Y_{i}$ if and only if $\theta<1(\theta>1)$, and $l(E):=E_{i}^{\bar{\theta}} \mu_{\mathrm{WTP}}$ is a convex (concave) function of $E_{i}$ if and only if $\theta<1(\theta>1)$. Then by Jensen's inequality, $\mu_{\mathrm{WTP}}$ is increased (decreased) by any mean preserving spread in $Y$ in case of complements (substitutes). The same holds true for $E$ : $\mu_{\mathrm{WTP}}$ is increased (decreased) by any mean preserving spread in $E$ in case of complements (substitutes).

\subsection{Household's WTP as Compensating Surplus}

The compensating surplus, $c_{i}$, is defined as $U\left(X_{i}-c_{i}, E_{i}^{\prime}\right)=U\left(X_{i}, E_{i}\right)$ for a change in the environmental good from $E_{i}$ to $E_{i}^{\prime}$. For a marginal increase in the environmental good, $E_{i}^{\prime}=E_{i}+d E_{i}$, the WTP reads

$$
\begin{gathered}
U\left(X_{i}-\mathrm{WTP}, E_{i}+d E_{i}\right)=U\left(X_{i}, E_{i}\right) \\
\stackrel{E q \cdot(1)}{\Rightarrow}\left(\alpha\left(X_{i}-\mathrm{WTP}_{i}\right)^{\frac{\theta-1}{\theta}}+(1-\alpha)\left(E_{i}+d E_{i}\right)^{\frac{\theta-1}{\theta}}\right)^{\frac{\theta}{\theta-1}}=\left(\alpha X_{i}^{\frac{\theta-1}{\theta}}+(1-\alpha) E_{i}^{\frac{\theta-1}{\theta}}\right)^{\frac{\theta}{\theta-1}} \\
\stackrel{X_{i}=Y_{i} / P}{\Longleftrightarrow} \alpha\left(\frac{Y_{i}}{P}-\mathrm{WTP}_{i}\right)^{\frac{\theta-1}{\theta}}+(1-\alpha)\left(E_{i}+d E_{i}\right)^{\frac{\theta-1}{\theta}}=\alpha\left(\frac{Y_{i}}{P}\right)^{\frac{\theta-1}{\theta}}+(1-\alpha) E_{i}^{\frac{\theta-1}{\theta}}
\end{gathered}
$$

Using Taylor-series expansion of degree one at WTP $=0$ and $d E_{i}=0$

$$
\begin{gathered}
\left(\frac{Y_{i}}{P}-\mathrm{WTP}\right)^{\frac{\theta-1}{\theta}} \approx\left(\frac{Y_{i}}{P}\right)^{\frac{\theta-1}{\theta}}-\frac{\theta-1}{\theta}\left(\frac{Y_{i}}{P}\right)^{-1 / \theta} \mathrm{WTP} \\
\left(E_{i}+d E_{i}\right)^{\frac{\theta-1}{\theta}} \approx E_{i}^{\frac{\theta-1}{\theta}}+\frac{\theta-1}{\theta} E_{i}^{-1 / \theta} d E_{i},
\end{gathered}
$$

in Eq. (54) and rearranging gives 


$$
\begin{gathered}
\operatorname{WTP}\left(Y_{i}, E_{i}\right)=\frac{(1-\alpha)}{\alpha} E_{i}^{-1 / \theta} Y_{i}^{1 / \theta} P^{-1 / \theta} d E_{i} \\
\stackrel{E q .(4)}{=} \frac{\omega\left(Y_{i}, E_{i}\right)}{P} d E_{i} .
\end{gathered}
$$

\subsection{Histograms on $Y$ and $E$ in Empirical Application (Sect. 4)}

See Figs. 3, 4 and 5.

Fig. 3 Histogram of the distribution of net monthly household income [in 2011-PLN] in Poland as assessed in the forest preservation survey by Czajkowski et al. (2014a)

Fig. 4 Histogram of the distribution of the inverse average Euclidean distance to the nearest forest ('forest proximity') from any point of the $10 \times 10 \mathrm{~km}^{2}$ grid square where respondent lives as used by Czajkowski et al. (2017)
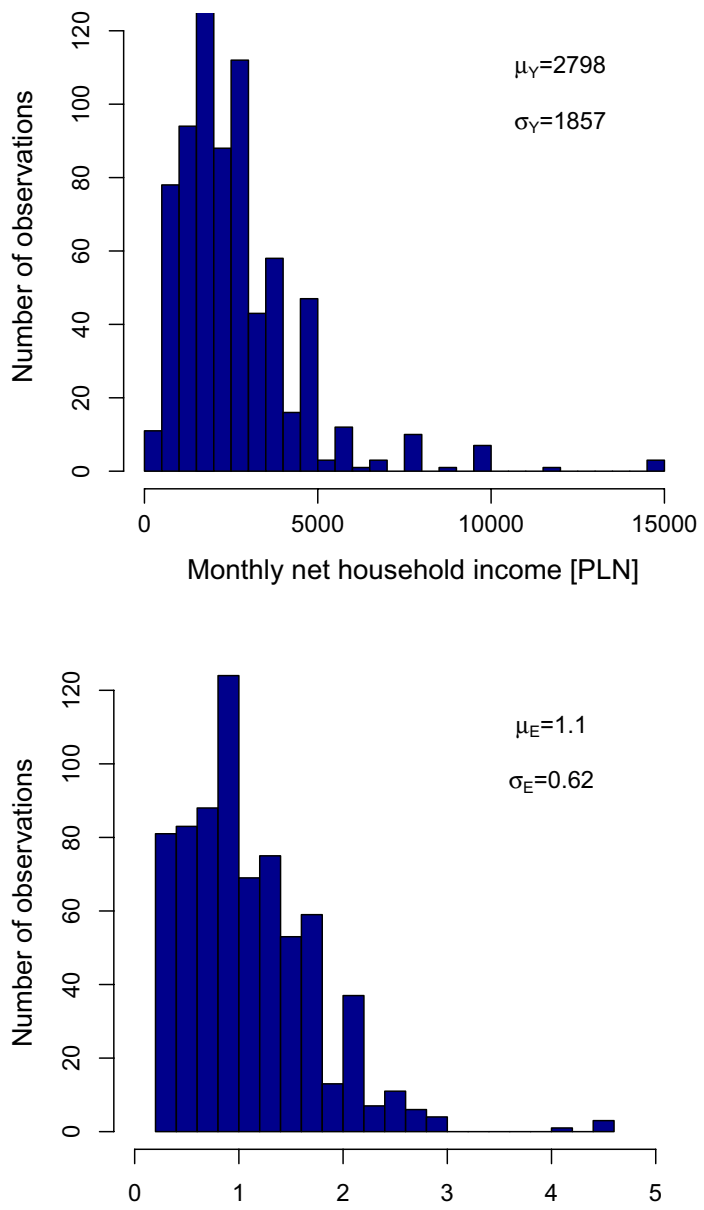

Inverse average distance to nearest forest $\left[\mathrm{km}^{\wedge}-1\right]$ 


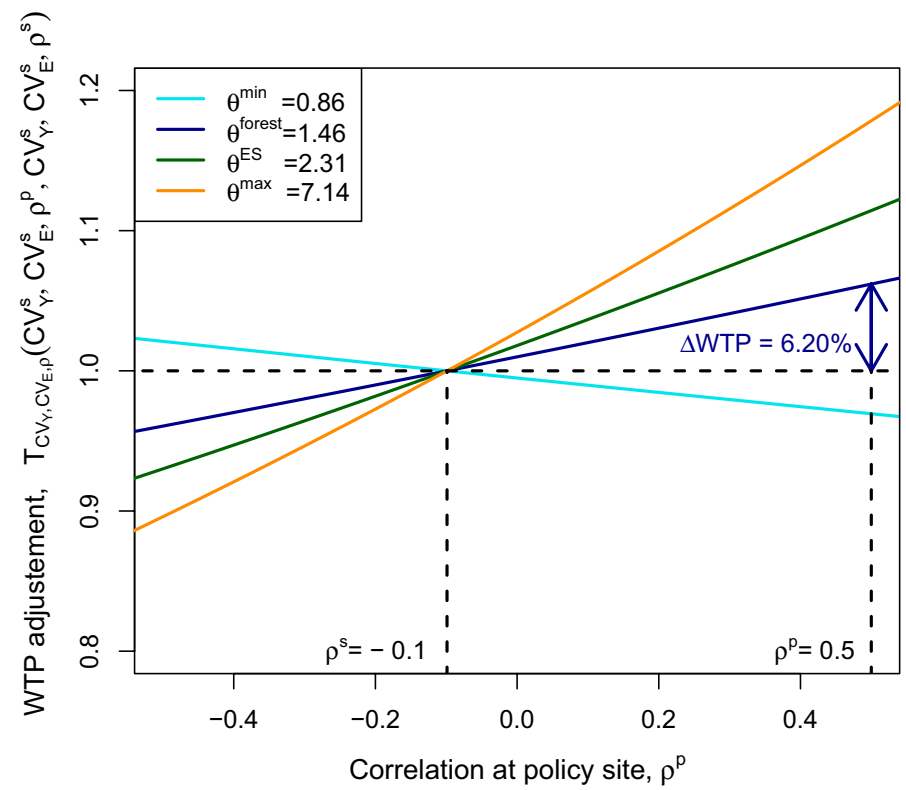

Fig. 5 Relationship between the transfer factor to adjust societal WTP for differences in the distribution of income and the environmental good, $\mathcal{T}_{\mathrm{CV}_{Y}, \mathrm{CV}_{F}, \rho}$, and different correlations of income and endowment with the environmental good at the policy site $\rho^{\mathrm{p}}$. In the hypothetical transfer depicted, the societal WTP for forest protection in Poland is adjusted to a situation where income inequality and environmental inequality is identical at study and policy site, but the correlation between $Y$ and $E$ differs

\section{References}

Aaron H, McGuire M (1970) Public goods and income distribution. Econometrica 38:907-919

Alvaredo F, Chancel L, Piketty T, Saez E, Sucman G (2017) World Inequality Report 2018. World Inequality Lab

Aronsson T, Johansson-Stenman O (2008) When the Joneses' consumption hurts: optimal public good provision and nonlinear income taxation. J Public Econ 92(5-6):986-997

Ash M, Fetter TR (2004) Who lives on the wrong side of the environmental tracks? Evidence from the EPA's risk-screening environmental indicators model. Soc Sci Q 85(2):441-462

Banzhaf S, Ma L, Timmins C (2019) Environmental justice: the economics of race, place, and pollution. J Econ Perspect 33(1):185-208

Barbier EB, Czajkowski M, Hanley N (2017) Is the income elasticity of the willingness to pay for pollution control constant? Environ Resource Econ 68(3):663-682

Bateman IJ, Brouwer R, Ferrini S, Schaafsma M, Barton DN, Dubgaard A, Hasler B, Hime S, Liekens I, Navrud S, De Nocker L, Šceponaviciute R, Semeniene D (2011) Making benefit transfers work: deriving and testing principles for value transfers for similar and dissimilar sites using a case study of the non-market benefits of water quality improvements across Europe. Environ Resource Econ 50(3):365-387

Bateman IJ, Day BH, Georgiou S, Lake I (2006) The aggregation of environmental benefit values: welfare measures, distance decay and total WTP. Ecol Econ 60(2):450-460

Baumgärtner S, Drupp MA, Munz J, Meya JN, Quaas MF (2017a) Income inequality and willingness to pay for environmental public goods. J Environ Econ Manag 85:35-61

Baumgärtner S, Drupp MA, Quaas MF (2017b) Subsistence, substitutability and sustainability in consumption. Environ Resource Econ 67(1):47-66

Baumgärtner S, Klein A-M, Thiel D, Winkler K (2015) Ramsey Discounting of Ecosystem Services. Environ Resource Econ 61:273-296 
Boyce JK, Zwickl K, Ash M (2016) Measuring environmental inequality. Ecol Econ 124:114-123

Boyle KJ, Kuminoff NV, Parmeter CF, Pope JC (2009) Necessary conditions for valid benefit transfers. Am J Agric Econ 91(5): 1328-1334

Brander LM, Bräuer I, Gerdes H, Ghermandi A, Kuik O, Markandya A, Kuik O, Markandy A, Navrund S, Nunes P, Marije S, Schafma M, Vos H, Wagtendonk A (2012) Using meta-analysis and GIS for value transfer and scaling up: valuing climate change induced losses of European wetlands. Environ Resource Econ 52(3):395-413

Brueckner JK, Thisse J-F, Zenou Y (1999) Why is central Paris rich and downtown Detroit poor? An amenity-based theory. Eur Econ Rev 43(1):91-107

Budziński W, Campbell D, Czajkowski M, Demsar U, Hanley N (2018) Using geographically weighted choice models to account for spatial heterogeneity of preferences. J Agric Econ 69:606-626

Butchart S, Walpole M, Collen B, van Strien A, Scharlemann J, Almond E, Baillie J, Bomhard B, Brown C, Bruno J, Carpenter K, Carr G, Chanson J, Chenery A, Csirke J, Davidson N, Dentner F, Foster M, Galli A, Galloway J, Genovesi P, Gregory R, Hockings M, Kapos V, Lamarque J, Leverington F, Loh J, McGeoch M, McRea L, Minayian A, Morcillo M, Oldfield T, Pauly D, Quader S, Revenga C, Sauer J, Skolnik B, Spear D, Stanwell-Smith D, Stuart S, Symes A, Tierney M, Tyrrell T, Vie J-C, Watson R (2010) Global biodiversity: indicators of recent declines. Science 328(5982):1164-1168

Government of Poland (2014) Fifth national report on the implementation of the convention on biological diversity. Government of Poland, Poland

Chancel L, Piketty T (2015) Carbon and Inequality from Kyoto to Paris: trends in the global inequality of carbon emissions (1998-2013) and prospects for an equitable adaptation fund. Paris school of economics

Chiabai A, Travisi CM, Markandya A, Ding H, Nunes PA (2011) Economic assessment of forest ecosystem services losses: cost of policy inaction. Environ Resource Econ 50(3):405-445

Currie J, Davis L, Greenstone M, Walker R (2015) Environmental health risks and housing values: evidence from 1,600 toxic plant openings and closings. Am Econ Rev 105(2):678-709

Czajkowski M, Budziński W, Campbell D, Giergiczny M, Hanley N (2017) Spatial heterogeneity of willingness to pay for forest management. Environ Resource Econ 68(3):705-727

Czajkowski M, Bartczak A, Giergiczny M, Navrud S, Żylicz T (2014a) Providing preference-based support for forest ecosystem service management. For Policy Econ 39:1-12

Czajkowski M, Giergiczny M, Greene WH (2014b) Learning and fatigue effects revisited. Investigating the effects of accounting for unobservable preference and scale heterogeneity. Land Econ 90(2):323-350

Czajkowski M, Ščasný M (2010) Study on benefit transfer in an international setting. How to improve welfare estimates in the case of the countries' income heterogeneity? Ecol Econ 69(12):2409-2416

Czajkowski M, Buszko-Briggs M, Hanley N (2009) Valuing changes in forest biodiversity. Ecol Econ 68(12):2910-2917

Di Q, Wang Y, Zanobetti A, Wang Y, Koutrakis P, Choirat C, Dominici F, Schwartz JD (2017) Air pollution and mortality in the Medicare population. N Engl J Med 376(26):2513-2522

Drupp MA (2018) Limits to substitution between ecosystem services and manufactured goods and implications for social discounting. Environ Resource Econ 69(1):135-158

Drupp MA, Meya JN, Baumgärtner S, Quaas MF (2018) Economic inequality and the value of nature. Ecol Econ 150:340-345

Ebert U (2003) Environmental goods and the distribution of income. Environ Resource Econ 25(4):435-459

Epple D, Romer T (1991) Mobility and redistribution. J Polit Econ 99(4):828-858

Epple D, Platt GJ (1998) Equilibrium and local redistribution in an urban economy when households differ in both preferences and incomes. J Urban Econ 43(1):23-51

Epple D, Sieg H (1999) Estimating equilibrium models of local jurisdictions. J Polit Econ 107(4):645-681

European Commission (2013) The economic benefits of the Natura 2000 network. Synthesis report. Publications Office of the European Union, Luxembourg

FAO (2016) State of the World's Forests 2016. Forests and agriculture: land-use challenges and opportunities. FAO, Rome

Flores NE, Carson RT (1997) The relationship between the income elasticities of demand and willingness to pay. J Environ Econ Manag 33(3):287-295

Heblich S, Trew A, Zylberberg Y (2018) East side story: historical pollution and persistent neighborhood sorting. University of St. Andrews School of Economics and Finance Online Discussion Paper Series, No. 1613

Hsiang S, Oliva P, Walker R (2019) The distribution of environmental damages. Rev Environ Econ Policy 13(1):83-103 
IPBES (2019) Global assessment report on biodiversity and ecosystem services of the Intergovernmental Science-Policy Platform on Biodiversity and Ecosystem Services. In: Brondizio ES, Settele J, Díaz S, Ngo HT (eds) IPBES secretariat, Bonn, Germany

Jacobsen J, Hanley N (2009) Are there income effects on global willingness to pay for biodiversity conservation? Environ Resource Econ 43(2):137-160

Jensen CU, Panduro TE, Lundhede TH, von Graevenitz K, Thorsen BJ (2016) Robin Hood in reverse? Assessing distributional effects of green space policy using a second-stage hedonic house price model IFRO Working Paper 2016, No 2016-07

Kovenock D, Sadka E (1981) Progression under the benefit approach to the theory of taxation. Econ Lett 8:95-99

Kriström B, Riera P (1996) Is the income elasticity of environmental improvements less than one? Environ Resource Econ 7:45-55

Kuminoff NV (2018) Can understanding spatial equilibria enhance benefit transfers for environmental policy evaluation? Environ Resource Econ 69:591-608

Kuminoff NV, Smith VK, Timmins C (2013) The new economics of equilibrium sorting and policy evaluation using housing markets. J Econ Lit 51(4):1007-1062

Lee S, Lin J (2018) Natural amenities, neighbourhood dynamics, and persistence in the spatial distribution of income. Rev Econ Stud 85:663-694

Loomis JB (2000) Vertically summing public good demand curves: an empirical comparison of economic versus political jurisdictions. Land Econ 76(2):312-321

Loomis JB (1992) The evolution of a more rigorous approach to benefit transfer: benefit function transfer. Water Resource Res 28:701-705

MacKerron G, Mourato S (2009) Life satisfaction and air quality in London. Ecol Econ 68(5):1441-1453

Millennium ecosystem assessment (2005) Ecosystems and human well-being: biodiversity synthesis. Published by World Resources Institute, Washington, DC

Meya JN, Drupp MA, Baumgärtner S, Quaas MF (2018) Inter- and intragenerational distribution and the valuation of natural capital. WCERE 2018 conference paper

Meya JN, Drupp MA, Hanley N (2020) Testing Structural Benefit Transfer: The Role of Income Inequality. Kiel Economics Working Paper, No 2017-03. Updated working paper

Moeltner K (2019) Bayesian nonlinear meta regression for benefit transfer. J Environ Econ Manag 93:44-62

Newbold SC, Walsh PJ, Massey DM, Hewitt J (2018) Using structural restrictions to achieve theoretical consistency in benefit transfers. Environ Resource Econ 69(3):529-553

[OECD 2018] Atkinson G, Braathen NA, Groom B, Mourato S (2018) Cost-benefit analysis and the environment: further developments and policy use. OECD Publishing, Paris

Pearce D, Atkinson G, Mourato S (2006) Cost-benefit analysis and the environment: recent developments. Organisation for Economic Co-operation and Development (OECD), Paris

Perino G, Andrews B, Kontoleon A, Bateman I (2014) The value of urban green space in Britain: a methodological framework for spatially referenced benefit transfer. Environ Resource Econ 57(2):251-272

Pinkovskiy M, Sala-i-Martin X (2009) Parametric estimations of the world distribution of income, NBER Working Paper No. 15433

Phaneuf DJ, Requate T (2017) A course in environmental economics: theory, policy, and practice. Cambridge University Press, Cambridge

Richardson L, Loomis J, Kroeger T, Casey F (2015) The role of benefit transfer in ecosystem service valuation. Ecol Econ 115:51-58

SCBD (Secretariat of the Convention on Biological Diversity) (2001) The value of forest ecosystems. Montreal, SCBD, CBD Technical Series, 4

Schlenker W, Walker WR (2015) Airports, air pollution, and contemporaneous health. Rev Econ Stud 83(2):768-809

Smith VK, Sieg H, Banzhaf HS, Walsh RP (2004) General equilibrium benefits for environmental improvements: projected ozone reductions under EPA's Prospective Analysis for the Los Angeles air basin. J Environ Econ Manag 47(3):559-584

Smith VK (1993) Nonmarket valuation of environmental resources: an interpretive appraisal. Land Econ 69:1-26

Smith VK, Van Houtven G, Pattanayak SK (2002) Benefit transfer via preference calibration: "Prudential algebra" for policy. Land Econ 78(1):132-152

Tan PY, Samsudin R (2017) Effects of spatial scale on assessment of spatial equity of urban park provision. Landsc Urban Plan 158:139-154

Tiebout C (1956) A pure theory of local expenditures. J Polit Econ 64(5):416-24 
Turner MA (2017) Benefit-transfer and spatial equilibrium. Environ Resource Econ 69:575-589

United Nations, European Commission, Food and Agriculture Organization of the United Nations, Organisation for Economic Co-operation and Development, World Bank Group (2014) System of Environmental-Economic Accounting 2012-Experimental Ecosystem Accounting. United Nations, New York

World Bank, Lange G-M, Wodon Q, Carey K (2018) The Changing Wealth of Nations 2018: building a sustainable future Washington. World Bank, DC. https://doi.org/10.1596/978-1-4648-1046-6

Yue S (2000) The bivariate lognormal distribution to model a multivariate flood episode. Hydrol Process $14: 2575-2588$

Zaidi S (2009) Main drivers of income inequality in central European and Baltic countries-some insights from recent household survey data. The World Bank, Policy Research Working Paper, 4815

Publisher's Note Springer Nature remains neutral with regard to jurisdictional claims in published maps and institutional affiliations. 